\title{
Oak Ridge Environmental Information System (OREIS) Phase I-System Definition Document
}

\author{
Environmental Restoration Division \\ P.O. Box 2003 \\ Oak Ridge, Tennessee 37831-7256
}

Date Issued-June 1992

Prepared by

Oak Ridge Environmental Information System (OREIS)

Oak Ridge National Laboratory

Prepared for

U.S. Department of Energy

Office of Environmental Restoration and Waste Management

under budget and reporting code EW 20

MARTIN MARIETTA ENERGY SYSTEMS, INC.

managing the

Oak Ridge K-25 Site

Oak Ridge Y'-12 Plant

Oak Ridge National Laboratory

under contract DE-AC05-84OP21400
Paducah Gaseous Diffusion Plant Portsmouth Gaseous Diffusion Plant under contract DE-AC05-760R00001

for the

U.S. DEPARTMENT OF ENERGY

DISTRIBUTION OF THE DOCUMENT IS UNLIMITED

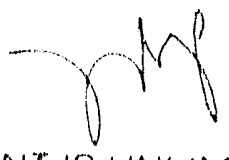


Oak Ridge Environmental Information System (OREIS) Team
L. D. Voorhees
R. A. MeCord
R. C. Durfee
J. C. Goyert
M. L. Land
R. J. Olson
J. K. Thomas
E. P. Tinnel

\section{Author Affiliations}

L. D. Voorhees, R. A. McCord, and R. J. Olson are members of the Environmental Sciences Division; R. C. Durfee and E. P. Tinnel are members of the Computing and Telecommunications Division; and J. K. Thomas and M. L. Land are members of the Health and Safety Research Division, Oak Ridge National Laboratory, Martin Marietta Energy Systems, Inc. J. C. Goyert is a member of SAIC, Oak Ridge office. 


\section{CONTENTS}

FIGURES AND TABLES

ABBREVIATIONS AND ACRONYMS EXECUTIVE SUMMARY

1. INTRODUCTION

2. BACKGROUND 2

3. INITLAL PLANNING EFFORTS $\ldots \ldots \ldots \ldots \ldots \ldots \ldots \ldots \ldots \ldots \ldots$

3.1 DATA NEEDS MEETING $\ldots \ldots \ldots \ldots \ldots \ldots \ldots \ldots \ldots \ldots \ldots$

3.2 CDB STEERING COMMITTEE $\ldots \ldots \ldots \ldots \ldots \ldots \ldots \ldots \ldots \ldots, 3$

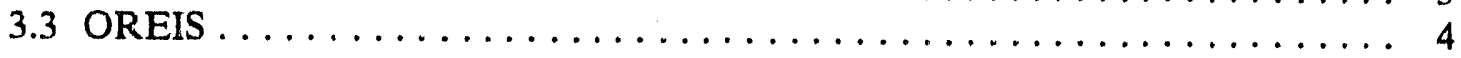

PART I: FEASIBILITY STUDY $\ldots \ldots \ldots \ldots \ldots \ldots \ldots \ldots \ldots \ldots \ldots$

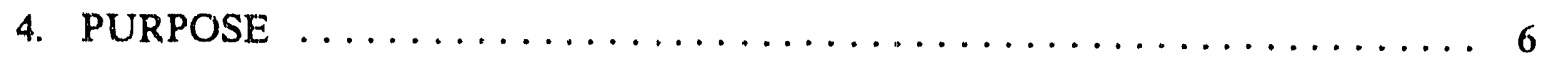

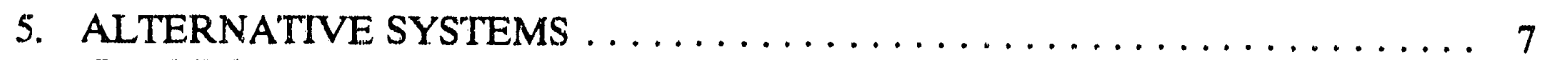

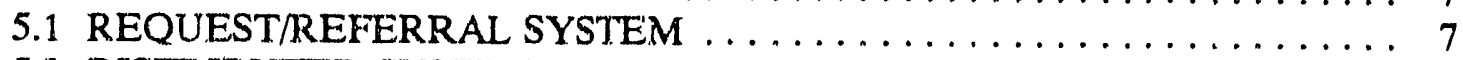

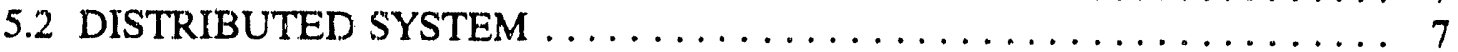

5.3 CENTRALIZED SYSTEM $\ldots \ldots \ldots \ldots \ldots \ldots \ldots \ldots \ldots \ldots \ldots, 7$

6. REVIEW OF CURRENT PRACTICES $\ldots \ldots \ldots \ldots \ldots \ldots \ldots \ldots$

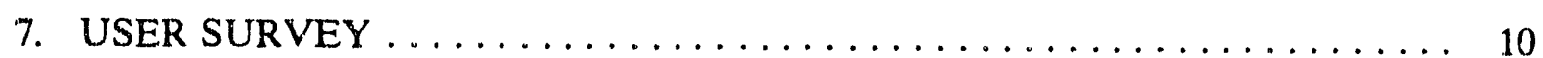

7.1 USER SURVEY RESULTS $\ldots \ldots \ldots \ldots \ldots \ldots \ldots \ldots \ldots \ldots, 10$

7.2 EXTENT OF DIVERSITY IN CURRENT PRACTICES $\ldots \ldots \ldots \ldots \ldots, 10$

7.2.1 Hardware, Software, and GIS Components . . . . . . . . . . . . 13

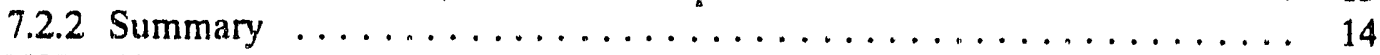

7.3 USERS' EXPECTATIONS FOR A CONSOLIDATED SYSTEM $\ldots \ldots, 15$

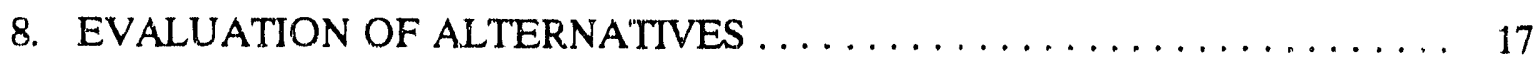

8.1 REQUEST/REFERRAL SYSTEM $\ldots \ldots \ldots \ldots \ldots \ldots \ldots \ldots \ldots, 17$

8.2 DISTRIBUTED SYSTEM $\ldots \ldots \ldots \ldots \ldots \ldots \ldots \ldots \ldots \ldots, 17$

8.3 CENTRALIZED SYSTEM $\ldots \ldots \ldots \ldots \ldots \ldots \ldots \ldots \ldots \ldots, 18$

9. OPERATIONAL AND DEVELOPMENTAL COMPARISONS $\ldots \ldots \ldots \ldots, 19$

9.1 OPERATIONAL CONSTRAINTS $\ldots \ldots \ldots \ldots \ldots \ldots \ldots \ldots \ldots \ldots$

9.2 PERFORMANCE FACTORS $\ldots \ldots \ldots \ldots \ldots \ldots \ldots \ldots \ldots \ldots \ldots$

10. SELECTION OF ALTERNATTVE $\ldots \ldots \ldots \ldots \ldots \ldots \ldots \ldots \ldots \ldots \ldots \ldots \ldots \ldots \ldots, 22$

PART II: SYSTEM REQUIREMENTS DEFINITTON $\ldots \ldots \ldots \ldots \ldots \ldots \ldots 23$

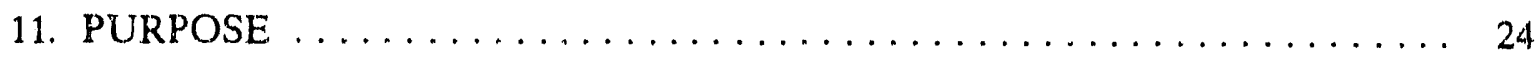

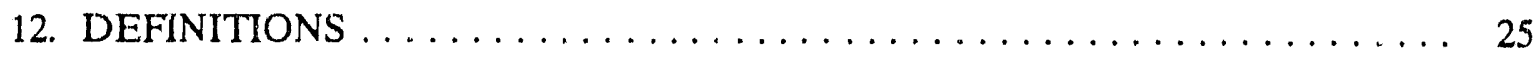


13. REQUIREMENTS .......................... 27

14. SYSTEM USERS . . . . . . . . . . . . . . . . . . . . . . . 29

14.1 ENVIRONMENTAL RESTORATION . . . . . . . . . . . . . . 29

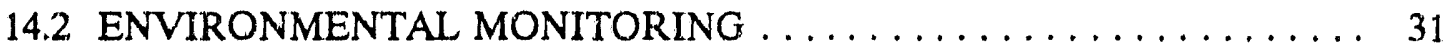

14.3 OTHER USERS $\ldots \ldots \ldots \ldots \ldots \ldots \ldots \ldots \ldots \ldots \ldots \ldots \ldots \ldots \ldots$

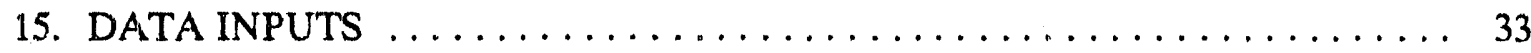

15.1 SOURCES OF ENVIRONMENTAL DATA $\ldots \ldots \ldots \ldots \ldots \ldots \ldots \ldots$

15.2 REQUIRED DATA TYPES $\ldots \ldots \ldots \ldots \ldots \ldots \ldots \ldots \ldots \ldots \ldots \ldots \ldots$

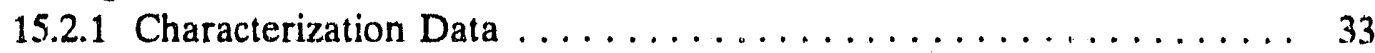

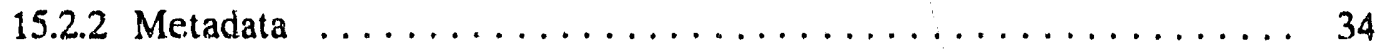

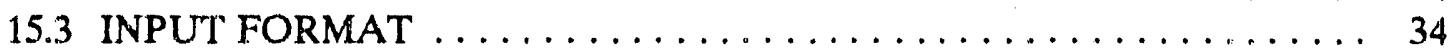

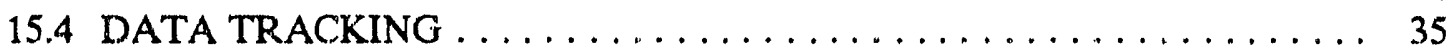

15.5 RESPONSIBILITIES ....................... 35

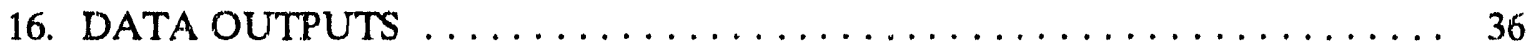

16.1 PRODUCT REQUIREMENTS $\ldots \ldots \ldots \ldots \ldots \ldots \ldots \ldots \ldots \ldots \ldots \ldots$

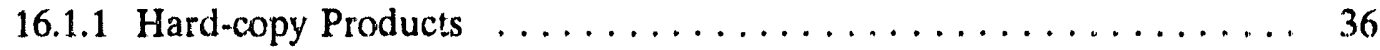

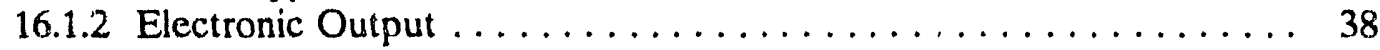

16.2 USER INTERFACE/QUERY SYSTEM $\ldots \ldots \ldots \ldots \ldots \ldots \ldots \ldots \ldots$

16.2.1 Menu System . . . . . . . . . . . . . . . . . . . 39

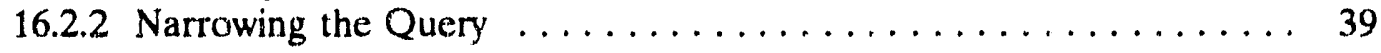

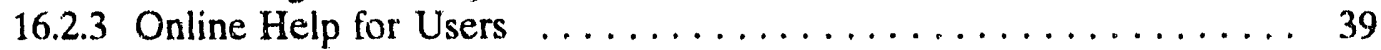

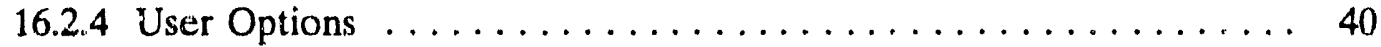

17. SYSTEM REQUIREMENTS $\ldots \ldots \ldots \ldots \ldots \ldots \ldots \ldots \ldots \ldots \ldots \ldots \ldots \ldots$

17.1 SECURITY REQUIREMENTS $\ldots \ldots \ldots \ldots \ldots \ldots \ldots \ldots \ldots \ldots \ldots \ldots$

17.2 QUALITY REQUIREMENTS $\ldots \ldots \ldots \ldots \ldots \ldots \ldots \ldots \ldots \ldots \ldots$. 41

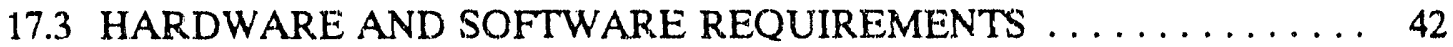

17.4 PROGRAMMING REQUIREMENTS $\ldots \ldots \ldots \ldots \ldots \ldots \ldots \ldots \ldots . \ldots 2$

17.5 STANDARDS AND PROCEDURF ${ }^{\imath} \ldots \ldots \ldots \ldots \ldots \ldots \ldots \ldots$

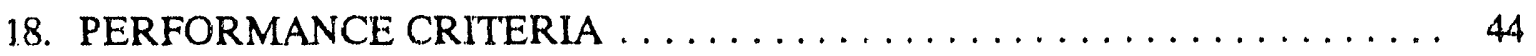

19. OUTSTANDING ISSUES $\ldots \ldots \ldots \ldots \ldots \ldots \ldots \ldots \ldots \ldots \ldots \ldots \ldots$

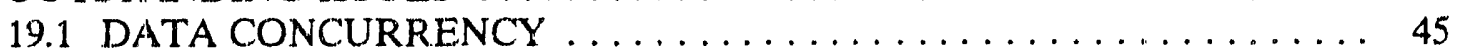

19.2 SUBCONTRACTOR EQUIPMENT $\ldots \ldots \ldots \ldots \ldots \ldots \ldots \ldots \ldots$

19.3 USER TRAINING $\ldots \ldots \ldots \ldots \ldots \ldots \ldots \ldots \ldots \ldots \ldots \ldots \ldots$

19.4 MIGRATION OF EXISTING ACTIVITIES AND DATA $\ldots \ldots \ldots \ldots .45$

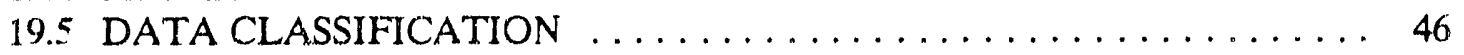

19.6 STANDARDS AND PROCEDURES $\ldots \ldots \ldots \ldots \ldots \ldots \ldots \ldots \ldots$

APPENDIX A............................ 48 


\section{FIGURE}

1 System design: Functional components of OREIS $\ldots \ldots \ldots \ldots \ldots \ldots \ldots \ldots \ldots$

\section{TABLES}

1 ER and EM staff participants in user survey $\ldots \ldots \ldots \ldots \ldots \ldots \ldots \ldots \ldots$

2 Data management requirements for $\mathrm{EM}$ and $\mathrm{SR}$ programs .............. 12

3 Subcontractors, hardware, software, and geographic information systems used at the five OR sites for EM and ER activities . . . . . . . . . . . . 13

4 Percentages of respondents in user survey ranking the importance of each proposed function for a consolidated system . . . . . . . . . . . . . 15

5 Comparison of alternatives by conformance to operational constraints . . . . . . 20

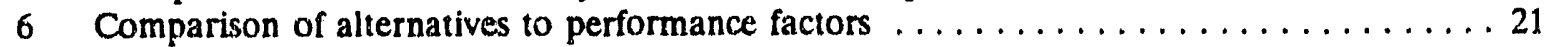

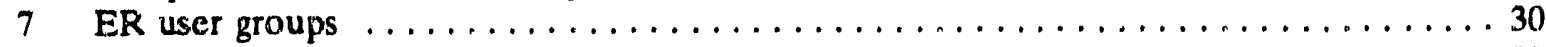

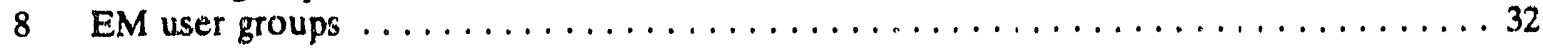




\title{
ABBREVIATIONS AND ACRONYMS
}

\author{
ADP SDM Automated Data Processing System Development Methodology \\ ARAR Applicable or Relevant and Appropriate Requirement \\ ATSDR Agency for Toxic Substances and Disease Registry \\ CERCLA Comprehensive Environmental Response, Compensation, and Liability Act \\ CDB Consolidated Data Base \\ DEC Digital Equipment Corporation \\ EM Environmental Monitoring \\ EPA Environmental Protection Agency \\ ER Environmental Restoration \\ FFA Federal Facilities Agreement \\ GIS Geographic Information System \\ IFF Interchange File Format \\ LIMS Laboratory Information Management System \\ MCL. Maximum Contaminant Level \\ NPDES National Pollutant Discharge Elimination System \\ NPL National Priority List \\ OR Department of Energy Oak Ridge Field Office \\ OREIS Oak Ridge Environmental Information System \\ ORNL Oak Ridge National Laboratory \\ ORR Oak Ridge Reservation \\ QA Quality Assurance \\ RCRA Resource Conservation and Recovery Act \\ RFI RCRA Facility Investigation \\ RI/FS Remedial Investigation/Feasibility Study (CERCLA) \\ TDEC Tennessee Department of Environment and Conservation
}




\section{EXECUTIVE SUMMARY}

The Phase I-System Definition Document documents the basis for establishing a consolidated environmental data base and information system for the Department of Energy Oak Ridge Field Office (OR) facilities operated by Martin Marietta Energy Systems, Inc. (Energy Systems). The Automated Data Processing System Development Methodology (ADP SDM), an Energy Systems procedure to assist in developing scientific and technical systems, was used to guide the preparation of the feasibility study and the system requirements definition, both of which are contained in this document.

The Feasibility Study (Part I) documents the existing system and data management practices and establishes and analyzes preliminary alternatives to be considered for the development of a consolidated system, i.e., the Oak Ridge Environmental Information System (OREIS). Alternatives were analyzed for technical and operational feasibility, benefits, and risks. Performance criteria used to rank alternatives included standardization, documentation, robustness, integration, reliability, and predictability. Of the three alternatives studied-request/referral, distributed, and centralized-the centralized system was selected to be most feasible because of its conformance to the performance criteria.

The System Requirements Definition (Part II) documents all of the components of the OREIS system and their intended interaction; specifically, it documents the proposed design principles to be implemented, the data sources to be supported, the user communities to be served, the types of data to be included, the data output requirements, the system access considerations, and the user interface requirements. Intended for use by system developers and potential users, it states the minimum specifications required by the system and establishes determinations on system operation and use. Part II contains both a master list and detailed description of the system requirements. 


\section{INTRODUCTION}

The purpose of the Phase I-System Definition Document is to document the basis for establishing a consolidated environmental data base and information system for Department of Energy Oak Ridge Field Office (OR) facilities operated by Martin Marietta Energy Systems, Inc. (Energy Systems). The Automated Data Processing System Development Methodology (ADP SDM) ${ }^{1}$, a Martin Marietta Energy Systems procedure to assist in developing scientific and technical systems, is being used to guide the development of the data base and information system.

This document addresses the feasibility study and the system requirements definition tasks assigned to Phase I of the project. The Feasibility Study (Part I) documents the existing systern and data management practices and establishes and analyzes preliminary alternatives to be considered for the development of a consolidated system, i.e., the Oak Ridge Environmental Information System (OREIS). Alternatives are analyzed for technical and operational feasibility, benefits, and risks. Part I also documents the establishment of performance criteria, the selection of the proposed alternative, and the assessment of the impact of the selected alternative on user staff. The System Requirements Definition (Part II) defines terms and documents the proposed design principles to be implemented, the data sources to be supported, the user communities to be served, the types of data to be included, the data output requirements, the system access considerations, and the user interface requirements.

Other documents prescribed by the ADP SDM for Phase II-System Design and Phase III-System Implementation include the quality assurance assessment plan; the functional system design document, which includes the data dictionary; the computer system design document; and the programming and implementation documents, which will include program documentation, a users' guide, and a computer operations manual. These documents will provide a step-by-step review of the development process undertaken for OREIS.

1 Automated Data Processing Systems Development Methodology, Vols. 1 and 2, 1990, (K/CSD/INF/86-3, Vol. 1 and Vol. 2) Computing and Telecornmunications Division, Martin Marietta Energy Systems, Oak Ridge, Tennessee. 


\section{BACKGROUND}

In 1989, the DOE Oak Ridge Reservation (ORR) was listed on the National Priority List (NPL), promulgated under Section 105 of the Comprehensive Environmental Response, Compensation, and Liability Act (CERCLA). In response to this action, a Federal Facility Agreement (FFA) between DOE, the U. S. Environmental Protection Agency (EPA), and the State of Tennessee Department of Environment and Conservation (TDEC) was signed in 1992. The FFA is a legally binding compliance agreement and requires the integration of all release-characterization dala on the ORR with all data generated by the Resource Conservation and Recovery Act (RCRA) and CERCLA investigations. The FFA specifies that

DOE shall maintain one consolidated data base for the Site which includes all data/studies generated pursuant to this Agreement and those generated under Federal and State environmental permits.

The consolidated data base will contain environmental measurement data from the five OR facilities that are managed by Energy Systems. These facilities include the Oak Ridge National Laboratory (ORNL), the K-25 Plant, the Y-12 Plant, and the gaseous diffusion plants located at Paducah, Kentucky, and Portsmouth, Ohio. Environmental data generated by off-site projects (e.g., Clinch River and East Fork Poplar Creek) will also be included in the consolidated data base.

To comply with the intent of the FFA for a consolidated environmental data base, the OR Environmental Restoration (ER.) Division and the Energy Systems ER Division appointed Larry Voorhees, Environmental Sciences Division, ORNL, to coordinate the OREIS-related planning and development activities. A Consolidated Data Base (CDB) Steering Committee was established to assist in the planning efforts. 


\section{INITIAL PLANNING EFFORTS}

The primary purpose of OREIS is to support environmental restoration planning and decision making. The overall goal is to develop a system to make environmental data accessible by multiple groups in a predictable manner with respect to format, quality, and the effort required to obtain data. Objectives of OREIS are (1) to ensure long-term retention and accessibility of data collected at all sites, (2) to support the development of a common format for reporting environmental monitoring data, and (3) to facilitate the sharing of data in support of environmental monitoring and environmental restoration assessments. Additional benefits anticipated from the consolidation of environmental data include using the data for problem identification; conducting remediation studies, site characterizations, groundwater analyses, and environmental impact assessments; and facility management.

The development of OREIS is guided by the following principles:

- The system will be developed in phases, focusing initially on environmental restoration data, and later incorporating compliance monitoring data.

- Users of data will be involved in all phases of the development process.

- Existing hardware and software systems will be used whenever possible.

- Existing data management activities will be integrated into the development process to the extent possible; changes in current data management activities conducted at each facility will be minimized.

- Commercially available, off-the-shelf, fully supported software will be used whenever possible.

- The system will ensure utility (ease of use, modifications, updates, enhancements).

- The system will have capabilities to maintain security and quality assurance of data.

\subsection{DATA NEEDS MEETING}

In February 1990, a one-day meeting was held in Oak Ridge to allow a forum for EPA, TDEC, and the Agency for Toxic Substances and Disease Registry (ATSDR) to discuss their specific data needs with ORR data generators and data managers. An agenda, a list of participants, and the minutes of this meeting are on file at Energy Systems' ER Document Management Center.

\subsection{CDB STEERING COMMITTEE}

Following the Data Needs Meeting, a steering committee, consisting of representatives from ER programs at each of the five OR facilities, was formed to provide technical expertise for the design, development, and implementation of the consolidated environmental data base system based on the overall goal, objectives, and guid:ng principles established during initial 
planning. The steering committee consists of data users and data managers representing each site and off-site project. A list of steering committee members and minutes of the steering committee meetings are on file at the ER Document Management Center.

\subsection{OREIS}

OREIS was conceived from the meetings held by the CDB steering committee and its various subcommittees. OREIS is a set of plans, procedures, data bases, and computerized application programs designed to facilitate the acquisition, management, and analysis of environmental-characterization data and information used in support of regulatory decisions. OREIS will be designed to support data management functions associated with environmental restoration at the five OR sites and to meet the requirements of the FFA. The data bases of OREIS will serve as the centralized repository containing both environmental restoration data and environmental characterization data and information collected by other environmental programs, including environmental monitoring and site groundwater-assessment programs. The evolution of OREIS through the first phase of development is recorded in this document. 
PART I: FEASIBILITY STUDY 


\section{PURPOSE}

The purpose of this feasibility study was to gather sufficient information concerning current and desired dita management and reporting practices to identify a preferred alternative for OREIS that would meet both FFA and user requirements. Because many environmental data maragement operations already exist within Energy Systems, the primary guiding principle for defining a consolidated system was to select a system that would consolidate and enhance current data processing activities with rainimal impact to curreni data generators and data users.

The feasibility study process included identifying three system design alternatives, designing and administering a user survey to assist the $C D B$ steering committee to further define current data management practices, and analyzing the benefits and risks of each alternative and their impact on data users. 


\section{ALTERNATIVE SYSTR.MS}

The system of OREIS, as concen!ualized, would include plans, procedures, data bases, the computer system, the applications programs, and staff. Its development must rely on the interaction and coordination of many people, pre grams, sites, and projects that currently work somewhat independently. The selected alternative must encompass and consider all of these factors. The three alternative systems considered for selection for OKEIS included (1) a request/referral system, (2) a distributed system, and (3) a centralized system.

\subsection{REQUEST/REFERRAL SYSTEM}

The request/referral system would contain a collection of different types of data bases that would be accessed, supported, and operated by a team of data specialists. These data specialists would be responsible for all data access, analysis, distribution, and reporting activities. This approach would keep the data responsibilities closest to the data generators. The collection of data bases could be distributed across a variety of different software and hardware systems. This alternative depends on the data specialists maintaining continuous familiarity with the format and status of the data needed for the consolidated system. The most aggregated type of information in this alternative would be some form of a data dictionary to guide the specialists in their activities. The user would not have direct access to data because of the multiple data structures and multiple locations of the individual data files. In a request/referral system, users would request a subset of the data base, generally in electronic format, for uploading to their computer system for subsequent data analysis, mapping, and reporting.

\subsection{DISTRIBUTED SYSTEM}

In the distributed system, data would be stored in a number of remotely accessible data bases, generally near the source of the data collection effort, and a variety of software and hardware configurations would be used. The data could also be in different, but consistent, formats. The data bases could be accessed directly by the user through a common user interface or gateway system. A distributed data base system is similar to the request/referral system in that it is often distributed across a variety of hardware platforms. It differs from the request/referral system in that it is limited to those configurations that can be accessed remotely and automatically from a common user interface. Remote and automatic access means that the data can either be accessed and analyzed directly from the data generator's system, or it can be electronically translated as needed from this system into the consolidated system. A substantial portion of analysis, mapping, and report generation could be performed by the user with the gateway interface. The distributed system may or may not include a menu and map-based user interface.

\subsection{CENTRALIZED SYSTEM}

In a centralized system, data would be stored at a centrally located facility in a consistent, standardized format. The data collection and initial processing may be performed by the data 
generators with validated data transferred to OREIS. One or more actual systems may be used. The data could be easily and consistently accessed by users who are connected directly to the centralized facility. A centralized clata base has a fairly restricted variety of hardware and software systems that contain its data. If the centralized data are distributed across more than one system, then access between the systems would be fully transparent to the user. The centralized data base alternative would also inciude capabilities to perform a majority of the analyses, mapping, and report generation functions. This alternative is also likely to include a menu and map-based interface to assist the user. 


\section{REVIEW OF CURRENT PRACTICES}

The development of OREIS could not be accomplished without first considering current data management practices at the five OR facilities. Many data management systems are already in place and each is able to meet its current needs. The challenge of integrating all of the key data management activities into a single system requires an appreciation for numerous areas of concern including hardware, software, rommunications, data collection procedures, data entry, variable naming conventions, chemical nomenclature, units of measurement, levels of precision, date and time formats, spatial coordinates, missing values, quality assurance (QA) elements, security, data exchange formats and procedures, and documentation.

An initial review of the various hardware systems ${ }^{2}$ showed that over 200 mainframe and minicomputer systems are used at Energy Systems in Oak Ridge. Most of these systems are dedicated to specific projects or types of work and are owned and operated by particular divisions or groups. The remainder are general-purpose systems known as, the Central Computing Systems, which include a Cray computer, several IBM and IBM-compatible mainframe computers, and numerous Digital Equipment Corporation (DEC) machines. The Central Computing Systems are operated by Energy Systerns' Computing and Telecommunications Division, but are available to a broad spectrum of users through a variety of networks.

Current data management practices at the $O R$ sites vary greatly. Even though a single ORR Environmental Report is published annually, each facility conducts its own data management. Further, many data types are managed independently at each site (i.e., no central collection of data at the site level). The only common data management factor among most of the five sites is the use of SAS software as the primary data management and analysis tool.

The need to further define current data management practices at each of the sites was addressed through the development of a user survey. The survey was used to assess users' needs and requirements for a consolidated system.

2 Voorhees, Larry D. Development of a Consolidated Environmental Data Base. Presented at the Data and Aualysis and Interpretation for Environmental Surveillance Conference, Lexington, Kentucky, Febneary 5-7, 1990. 


\section{USER SURVEY}

To assist the CDB steering committee in determining a feasible system, a Survey of Data Management and Information Needs Related to the Development of the Energy Systems Consolidated Environmental Data Base was designed and administered to data users and managers in both the environmental restoration and environmental monitoring programs to (1) determine data users' current data management and reporting practices and (2) to determine data users' expectations or requirements for a consolidated data base system. The survey instrument is attached as Appendix A. The survey addressed the following topics:

- Current practices. What is the diversity of current data management practices? What is the diversity of current hardware and software systems? What is the accessibility of these systems?

- Data content. What is the diversity of data needs by the user? Are the data needs frequently multidisciplinary! Are users regularly exchanging data? Could users benefit from readily accessible data? What portion of data needs is being handled directly by the user?

- Data distribution. What is the current distribution of environmental data? How many different groups have the same types of data? Are the data bases segregated by environmental category or are they multidisciplinary?

- Functions and applications. What kinds of functions should the consolidated system provide? Should the system be more than a repository (archive) of the information and, if so, which of these functions should the system provide: data management, QA, analyses, report generation, mapping, graphics, Geographic Information Systems (GIS)?

\subsection{USER SURVEY RESULTS}

The user survey was conducted by interviewing data management personnel from the Environmental Monitoring (EM) and ER organizations at all five OR sites. The staff listed in Table 1 either filled out the survey questionnaire or were personally interviewed or both. At least one representative from each of the five sites for both the ER and EM programs was contacted to discuss current data management activities. The survey was also distributed to members of the CDB steering committee for their review and input.

\subsection{EXTENT OF DIVERSITY IN CURRENT PRACTICES}

Management of environmental information is currently being conducted by both ER and EM programs at each site. These programs are administratively distinct entities with distinct requirements that are reflected in their data management objectives. ER programs collect various types of data for various needs depending on the specific remediation problem being addressed. EM programs collect routine information for periodic reports required to maintain environmental permits. 
Table 1. ER and EM staff participants in user survey

\begin{tabular}{|c|c|c|}
\hline Participant & Plant & Program \\
\hline Les Hook & $X-10$ & Environmental Restoration \\
\hline Jon Goyert & $X-10$ & Environmental Restoration \\
\hline Raymond McCord & $X-10$ & Environmental Restoration \\
\hline Kevin Newman & $X-10$ & Environmental Restoration \\
\hline Larry Voorhees & $X-10$ & Environmental Restoration \\
\hline Karen Daniels & $X-10$ & Environmental Monitoring \\
\hline Mark Tardiff & $X-10$ & Environmental Monitoring \\
\hline Paul Baxter & $X-10$ & Groundwater Protection \\
\hline Tom Early & $X-10$ & Groundwater Protection \\
\hline Brenda Harrington & $X-10$ & Groundwater Protection \\
\hline Dale Huff & $X-10$ & Groundwater Protection \\
\hline Vicki Brumback & $\mathrm{Y}-12$ & Environmental Restoration \\
\hline Greg Underberg & $\mathrm{Y}-12$ & Environmental Restoration \\
\hline Kim Hanzelka & $\mathrm{Y}-12$ & Environmental Monitoring \\
\hline Charlotte Kimbrough & $\mathrm{Y}-12$ & Environmental Monitoring \\
\hline Helen King & $Y-12$ & Environmental Monitoring \\
\hline Wayne McMahon & $Y-12$ & Environmental Monitoring \\
\hline Terre Mercier & $\mathrm{Y}-12$ & Environmental Monitoring \\
\hline Patty Goddard & $\mathrm{K}-25$ & Environmental Restoration \\
\hline Miriam Land & $\mathrm{K}-25$ & Environmental Restoration \\
\hline Denise Miller & $\mathrm{K}-25$ & Environmental Restoration \\
\hline Bonnie Shoemaker & $\mathrm{K}-25$ & Environmental Monitoring \\
\hline Richard Meehan & Portsmouth & Environmental Restoration \\
\hline Keith Bracknell & Portsmouth & Environmental Monitoring \\
\hline Richard Grant & Portsmouth & Environmental Monitoring \\
\hline Bruce Meadows & Paducah & Environmental Restoration \\
\hline Ken Davis & Paducah & Environmental Restoration \\
\hline Mitzi Guhy & Paducah & Environmental Monitoring \\
\hline
\end{tabular}


Table 2 summarizes the data management requirements for both ER and EM programs. The user survey also verified that neither the ER or the EM program has a homogenous approach to environmental data management.

Table 2. Data management requirements for EM and ER programs

\begin{tabular}{|c|c|c|}
\hline FEATURE & $\begin{array}{c}\text { ENVIRONMENTAL } \\
\text { MONITORING }\end{array}$ & $\begin{array}{l}\text { ENVIRONMENTAL } \\
\text { RESTORATION }\end{array}$ \\
\hline Scope of data & $\begin{array}{l}\text { Routine, periodic, somewhat } \\
\text { predictable }\end{array}$ & $\begin{array}{l}\text { Varied, problem-specific, } \\
\text { unpredictable }\end{array}$ \\
\hline Data applications & $\begin{array}{l}\text { Standard reports (tables, } \\
\text { graphs, and maps) required } \\
\text { by permits }\end{array}$ & $\begin{array}{l}\text { Varied tabulation, statistical } \\
\text { analyses, simulations and } \\
\text { projections; maps as needed } \\
\text { for specific problems }\end{array}$ \\
\hline Data sources and distribution & $\begin{array}{l}\text { Generates all of the required } \\
\text { data; limited dependency on } \\
\text { subcontractors; very little } \\
\text { data distribution within their } \\
\text { program; very low } \\
\text { requirement for other data }\end{array}$ & $\begin{array}{l}\text { Generates a portion of the } \\
\text { required data, significant } \\
\text { portion performed by } \\
\text { subcontractors; incorporates } \\
\text { historical and current } \\
\text { monitoring data; distributes } \\
\text { data to subcontractors }\end{array}$ \\
\hline Time frame of interest & $\begin{array}{l}\text { Current time period (month, } \\
\text { quarter, year) }\end{array}$ & $\begin{array}{l}\text { Current and future } \\
\text { operations; strong interest } \\
\text { in historical data for site } \\
\text { characterization }\end{array}$ \\
\hline Data structure & By environmental discipline & By project; part by site \\
\hline QA data & $\begin{array}{l}\text { Managed, processed, and } \\
\text { retained by labs }\end{array}$ & $\begin{array}{l}\text { Managed, processed, and } \\
\text { retained by labs and } \\
\text { projects }\end{array}$ \\
\hline History of operation & $15-20$ years & $1-4$ years \\
\hline Future operations & $\begin{array}{l}\text { Will evolve from current } \\
\text { approaches to OREIS }\end{array}$ & $\begin{array}{l}\text { Will evolve from current } \\
\text { approaches to OREIS }\end{array}$ \\
\hline $\begin{array}{l}\text { Level of homogeneity and } \\
\text { standardization }\end{array}$ & $\begin{array}{l}\text { Somewhat standardized } \\
\text { within an environmental } \\
\text { discipline at a site }\end{array}$ & $\begin{array}{l}\text { Somewhat standardized } \\
\text { within each project }\end{array}$ \\
\hline
\end{tabular}




\subsection{Hardware, Software, and GIS Components}

The survey showed a number of similarities and differences among ER and EM programs at the five sites in their use of various hardware, software, and GIS components (Table 3). All five sites use PCs in both ER and EM activities for some part of their work. In most

Table 3. Subcontractors, hardware, software, and geographic information systems used at the five OR sites for EM and ER activities

\begin{tabular}{|l|l|l|l|l||}
\hline ORGANIZATION & SUBCONTRACTOR & HARDWARE & SOFTWARE & \multicolumn{1}{|c|}{ GIS } \\
\hline ORNL ER & Bechtel National & IBM, VAX, PC & $\begin{array}{l}\text { SAS, } \\
\text { ORACLE, } \\
\text { LOTUS }\end{array}$ & ARC/INFO \\
\hline ORNL EM & None & IBM, VAX, PC & SAS, dBASE & None \\
\hline Y-12 ER & Geraghty \& Miller & VAX, PC & dBASE, SAS & $\begin{array}{l}\text { Generation } \\
\text { Five }\end{array}$ \\
\hline Y-12 EM & H\&R Technical & IBM, VAX, PC & $\begin{array}{l}\text { SAS, dBASE } \\
\text { LOTUS }\end{array}$ & None \\
\hline K-25 ER & None & PC & SAS, LOTUS & None \\
\hline K-25 EM & None & PC & SAS & None \\
\hline Portsmouth ER & Geraghty \& Miller & PC & ORACLE & $\begin{array}{l}\text { Generation } \\
\text { Five }\end{array}$ \\
\hline Portsmouth EM & Geraghty \& Miller & PC & $\begin{array}{l}\text { ORACLE, } \\
\text { dBASE }\end{array}$ & $\begin{array}{l}\text { Generation } \\
\text { Five }\end{array}$ \\
\hline Paducah ER & CH2MHill & VAX, PC & $\begin{array}{l}\text { INFORMIX, } \\
\text { ORACLE }\end{array}$ & $\begin{array}{l}\text { Generation } \\
\text { Five }\end{array}$ \\
\hline Paducah EM & None & VAX, PC & $\begin{array}{l}\text { TEAMUP, } \\
\text { ABASE, }\end{array}$ & None \\
\hline
\end{tabular}

cases, PCs were used for data entry and some spread sheet applications. In other cases (i.e., Portsmouth ER and EM programs) PCs are used for data storage, analysis, and mapping (using Generation Five). VAXes are primarily used to store the data generated by the analytical laboratories for subsequent transfer to various ER and EM systerns.

The Generation Five GIS is used at three of the five sites. It currently runs only in the PC environment, but a newer version is expected to be compatible with a number of Unix-based 
workstations. Except for Portsmouth, the EM organizations at each site have not historically used a GIS for the production of their annual reports. This practice may change due to the recent emphasis by OR on groundwater contamination problems, which can be more easily addressed by using a GIS tool.

SAS, running on IBMs, VAXes, and PCs, is the primary tool used by the sites in Oak Ridge to perform their data analysis and reporting activities. Portsmouth and Paducah use a combination of dBASE, ORACLE, and TEAMUP to perform these functions.

\subsubsection{Summary}

The heterogeneity of current practices for environrnental data management can be summarized by the following statements about major data management activities:

- Sampling and analysis planning information is stored using a variety of methods ranging from paper forms to electronic data bases.

- With the exception of the Y-12 Plant, all analytical laboratories operated by Energy Systems use AnaLIS, although each generates its own data formats from AnaLIS. The Y-12 Plant is currently converting from a Fortran-based system to a commercial laboratory information management system (LIMS). Subcontract analytical laboratories use other LIMS. Paducah EM relies on AnaL.IS for report generation.

- The QA of data has a varied meaning across the groups. Some groups depend on the analytical laboratory QA results; other groups manage the QA data and perform their own $\mathrm{QA}$ review.

- A wide range of hardware is used for data management and processing (e.g., PCs, VAXes, IBM mainframes). Parts of these systems are remotely accessible.

- A variety of software is used for data management and processing é.g. SAS, ORACLE, dBASE, INFORMIX, Lotus, Excell). The most common software used is SAS.

- There is no standardization in data base structure (e.g., data set contents, field names, field formats, qualifiers) between sites and programs.

- Data transfer between organizations is handled case by case. A small portion of the data transfer occurs on a routine basis with a standardized protocol.

- Data product generation occurs with a variety of methods. Some organizations generate products with tools closely connected to data management. Others transport portions of the data to additional software and hardware to generate data products. There is minimal standardization in product format and documentation.

- The documentation of data, data management procedures, and data product procedures is unstandardized and, in many cases, is missing altogether.

Overall, the current data management practices for environmental information are so diverse and undocumented that they are difficult to describe concisely. The implications of the current 
data management practices for implementation of a consolidated system will be discussed further in the following sections.

\subsection{USERS' EXPECTATIONS FOR A CONSOLIDATED SYSTEM}

The second objective of the user survey was to assess data users ${ }^{\circ}$ expectations for functions and applications needed from a consolidated system. Table 4 summarizes the responses obtained from the survey questionnaire on expected data functions and GIS functions of a consolidated system.

Table 4. Percentages of respondents in user survey ranking the importance of each proposed function for a consolidated system

\begin{tabular}{|c|c|c|c|c|}
\hline & ESSENTIAL & IMPORTANT & USEFUL & $\begin{array}{c}\text { NOT } \\
\text { NEEDED }\end{array}$ \\
\hline \multicolumn{5}{|l|}{ DATA FUNCTIONS } \\
\hline $\begin{array}{l}\text { Data merging } \\
\text { Data diversity } \\
\text { Data import/export } \\
\text { Data graphics } \\
\text { Data retrieval language } \\
\text { Documented editing } \\
\text { User interface } \\
\text { QA, stat, math } \\
\text { Relate to OREIS/GIS } \\
\text { Remote access } \\
\text { Report generation }\end{array}$ & $\begin{array}{r}100 \\
82 \\
82 \\
18 \\
73 \\
64 \\
73 \\
27 \\
36 \\
55 \\
64\end{array}$ & $\begin{array}{r}18 \\
18 \\
55 \\
9 \\
18 \\
9 \\
64 \\
55 \\
18 \\
27\end{array}$ & $\begin{array}{r}27 \\
9 \\
9 \\
18 \\
9 \\
9 \\
27 \\
9\end{array}$ & $\begin{array}{l}9 \\
9\end{array}$ \\
\hline \multicolumn{5}{|l|}{ GIS FUNCTIONS } \\
\hline $\begin{array}{l}\text { Access to OREIS } \\
\text { Digital data editing } \\
\text { Digital data import/export }\end{array}$ & $\begin{array}{l}64 \\
73 \\
91\end{array}$ & $\begin{array}{r}9 \\
27 \\
9\end{array}$ & 27 & \\
\hline Graphics inclusion & 27 & 55 & 9 & 9 \\
\hline $\begin{array}{l}\text { Known coordinate processing } \\
\text { Snatial data retrieval }\end{array}$ & $\begin{array}{r}100 \\
91\end{array}$ & 9 & & \\
\hline Network \& 3D analyses & 27 & 64 & 9 & \\
\hline Polygon processing & 60 & 40 & & \\
\hline Real map generation & 73 & 18 & 9 & \\
\hline Remote access & 40 & 40 & 20 & \\
\hline Structured digital GIS data & 90 & 10 & & \\
\hline User-friendly interface & 55 & 18 & 27 & \\
\hline
\end{tabular}

For data functions, all respondents (100\%) felt that data merging was essential. Other essential functions included data diversity $(82 \%)$, data import/export $(82 \%)$, data retrieval language $(73 \%)$, user interface $(73 \%)$, documented editing $(64 \%)$, report generation $(64 \%)$, 
and remote access (55\%). The functions most respondents felt were important, although not essential, were QA, statistics, and mathematical analyses $(64 \%)$, data graphics $(55 \%)$, and relationship to GIS (55\%).

Respondents felt that the following GIS functions were essential: known coordinate processing $(100 \%)$, digital data import/export $(91 \%)$, spatial data retrieval $(91 \%)$, and structured digital GIS data (90\%). Although only $27 \%$ of the respondents felt that functionality for network and 3D analyses was essential, $64 \%$ of the respondents considered this function to be important. 


\section{EVALUATION OF ALTERNATIVES}

The evaluation of each alternative includes a discussion of its advantages, disadvantages, and limitations.

\subsection{REQUEST/REFERRAL SYSTEM}

The major advantages of the request/referral alternative are that (1) it would require the least effort (software, equipment, and data conversion) to implement and (2) it would have the least impact on the existing data base management operations by keeping data closest to the data generators who maintain, update, and process it. However, this alternative would require data generators to follow standards.

The major disadvantages of this alternative are that (1) it would be operationaliy difficult to use and maintain because it would require extensive tracking and documentation to maintain a current, correct, and documented view of the data, (2) the documentation of the diverse and changing data bases would be extremely difficult and time consuming, (3) the system would require extensive staff time for the repeated merging of data from different sources, (4) the OREIS project would have little ability to predict or control the effort required to obtain a data product, (5) the data would have to be transported frequently between systems to provide the required data analysis activities (statistics, report generation, and mapping), and (6) a majority of the product quality would be subject to the skills of the data specialists.

The major limitation associated with the request/referral alternative would be to keep the data activities accurately and completely documented. When data are stored and retrieved by a variety of methods, it would be difficult to accurately document the origins of the data and data products. A second limitation of this alternative is its lack of responsiveness. The user would not have direct access to the data. The likelihood of success of this alternative is also limited by the requirement of frequent data transport between systems to provide the requested data products.

\subsection{DISTRIBUTED SYSTEM}

The major advantages of the distributed alternative are that it would (1) allow a portion of the ongoing data base activities to continue and to support OREIS, (2) spread the burden of data management over several organizations, and (3) provide a common computing environment for all OREIS data products (statistics, reports, and maps) as well as semiautomated access to a variety of data bases.

The major disadvantages of this alternative are (1) the number of gateways required to be developed (and maintained) to allow user access to all of distributed systems, (2) the need to have automatic access to current data systems as "distributed data" when most data are currently stored on stand-alone PC's and are not remotely accessible, and (3) the difficulty in providing accurate and timely documentation of the exact status of the data. 
The major limitation to implementing this alternative would be establishing direct access corunections to the data stored in the distributed systems. The best implementation of this alternative requires that the OREIS user be able to make direct access to the data on remote, distributed systems so that duplicate data sets are avoided. Direct access connections can be very difficult to develop and are best considered only when they are commercially available. Secondly, the translation of data between all of the distributed systems is a minimum requirement for a distributed data base. Similar to direct access connections, the development of reliable and efficient data translators can be difficult to implement and maintain. A distributed system would require that all data management be conducted on networked multiuser systems.

\subsection{CENTRALIZED SYSTEM}

The major advantages of the centralized alternative are that it would (1) provide a documentable and consistent operating environment for the generation of products, (2) minimize the problems associated with multiple copies or versions of the data, (3) be relatively simple to operate and maintain, (4) offer a comprehensive analysis capability in one system, (5) minimize the handling of data between systems, and (6) require the minimum amount of software development for implementation.

The major disadvantages of this alternative are that (1) it would require the purchase, configuration, and installation of hardware, software, and communication components that would be dedicated to the ER and EM programs and (2) the data would be maintained by people not directly involved in its generation and use.

The major limitation of this alternative is the acquisition and establishment of a system with sufficient resources and capability to meet the needs of the users. The transition from using existing systems to using OREIS will also require extensive planning and training. 


\section{OPERATIONAL AND DEVELOPMENTAL COMPARISONS}

The following general questions were considered during the comparison of each alternative:

- How well will each alternative conform to operational constraints?

- How responsive will each alternative be?

- What is the relative reliability of each alternative?

- How good is the optimum functionality of each alternative?

- What effort will be required to implement and operate each alternative?

- What limitations and problems are likely to remain unsolved for each aliernative?

\subsection{OPERATIONAL CONSTRAINTS}

Based on the need for OREIS to meet the requirements of the FFA, to maintain legally defensible data, and to meet user expectations, the system selected must be able to show conformance to the following six operational constraints: standardization, documentation, robustness, integration, reliability, and predictability. The system must be able to support and contribute to the standardization, or consistency, of data management activities for all organizations and programs. The system should be designed to automatically generate documentation for the user (e.g., audit trails and catalog of command scripts). The system should be robust, or be able to perform essentially all required data management functions. The system should be well integrated to ensure minimal effort for operational maintenance and to foster user acceptance. The system should also ensure reliability of the final data product and provide predictability with respect to format, quality, and utility.

Table 5 compares the likelihood that each alternative will meet these operational constraints for OREIS, using the following scoring system: 1 = favorable conformance;

$0=$ neutral/intermediate conformance; and $-1=$ unfavorable conformance. The comparison shows that the centralized system alternative has greater conformance to the performance constraints than the other alternatives have. The conformance of the distributed system to these constraints is dependent on the implementation of data access and translation capabilities. The request/referral alternative generally includes too great a diversity of activities to meet the constraints.

\subsection{PERFORMANCE FACTORS}

Table 6 compares each alternative based on five performance factors: responsiveness, reliability, optimum functionality, implementation and operation, and unresolved limitations and problems. The purpose of this exercise was to assess how responsive the system is likely to be to the needs of the user community; how likely the system is to generate a repeatable product; how much effort will be required to establish optimum functionality of the system; what the level of difficulty might be in implementing, operating, and maintaining the system; and what other issues may have an impact on the system. 
'Table 5. Comparison of alternatives by conformance to operational constraints'

\begin{tabular}{|c|c|c|c|}
\hline CONSTRAINT & REQUEST/REFIZRRAL & DISTRIBUTED & CENTRALIZEED \\
\hline Standardization & $\begin{array}{l}\text { Soore: }-1 \\
\text { Difficult to emulate a } \\
\text { unified "approach" }\end{array}$ & $\begin{array}{l}\text { Score: } 0 \\
\text { Essential for data } \\
\text { access between } \\
\text { distributed systems }\end{array}$ & $\begin{array}{l}\text { Score: } 1 \\
\text { A fundamental } \\
\text { element of this } \\
\text { alternative }\end{array}$ \\
\hline Documensation & $\begin{array}{l}\text { Soore: }-1 \\
\text { A continual challenge, } \\
\text { very voluminous, } \\
\text { extremely difficult to } \\
\text { manage correctly }\end{array}$ & $\begin{array}{l}\text { Score: } 1 \\
\text { A moderate amount } \\
\text { required; stability } \\
\text { could make it } \\
\text { manageable }\end{array}$ & $\begin{array}{l}\text { Sorore: } 1 \\
\text { Has the least } \\
\text { diversity of activities } \\
\text { to be documented }\end{array}$ \\
\hline Robustness & $\begin{array}{l}\text { Score: } 1 \\
\text { "Does it all"; includes all } \\
\text { existing operations }\end{array}$ & $\begin{array}{l}\text { Score: } 0 \\
\text { Does most operations; } \\
\text { has access to all data } \\
\text { systems }\end{array}$ & $\begin{array}{l}\text { Score: } 0 \\
\text { Cannot be all things } \\
\text { to all potential users; } \\
\text { priorities must be sel }\end{array}$ \\
\hline Integration & $\begin{array}{l}\text { Score: } 0 \\
\text { A loose integration } \\
\text { accomplished by the data } \\
\text { specialists for each system }\end{array}$ & $\begin{array}{l}\text { Score: } 0 \\
\text { Partially integrated } \\
\text { because of standards } \\
\text { required for data } \\
\text { access connections }\end{array}$ & $\begin{array}{l}\text { Score: } 0 \\
\text { Optimal integration; } \\
\text { data universally } \\
\text { available to all } \\
\text { functions }\end{array}$ \\
\hline Reliability & $\begin{array}{l}\text { Score: - } 1 \\
\text { Quessiona "a because of } \\
\text { diversity of activities }\end{array}$ & $\begin{array}{l}\text { Score: } 0 \\
\text { Uncertainty } \\
\text { dependent on success } \\
\text { of implementing and } \\
\text { maintaining data } \\
\text { access connections } \\
\text { and translators }\end{array}$ & $\begin{array}{l}\text { Scare: } 1 \\
\text { Uncertainty minimal; } \\
\text { only "one way" to } \\
\text { perform tasks; system } \\
\text { will have some } \\
\text { hardware and } \\
\text { software redundancy } \\
\text { to minimize } \\
\text { interruptions } \\
\end{array}$ \\
\hline Predictability & $\begin{array}{l}\text { Soore: }-1 \\
\text { Questionable because of } \\
\text { continual and partially } \\
\text { unknown status of data }\end{array}$ & $\begin{array}{l}\text { Score: } 0 \\
\text { Uncertainty } \\
\text { dependent on } \\
\text { continual maintenance } \\
\text { of data access } \\
\text { connestions and } \\
\text { translators }\end{array}$ & $\begin{array}{l}\text { Score: } 1 \\
\text { Minimal uncertainty; } \\
\text { tasks, pathways } \\
\text { required to generate } \\
\text { products are known }\end{array}$ \\
\hline Total score & $-m 3$ & 1 & 4 \\
\hline
\end{tabular}

The following scoring system was used to compare alternatives: $1=$ favorable conformance; $0=$ neutral/internediare conformance; and $-1=$ unfavorable conformance. 
Table 6. Comparison of alternatives by conformance to performance factors"

\begin{tabular}{|c|c|c|c|}
\hline $\begin{array}{l}\text { PERFORMANCE } \\
\text { FACTOR } \\
\end{array}$ & $\begin{array}{l}\text { REQUEST/ } \\
\text { REFERRAL }\end{array}$ & DISTRIBUTED & CENTRALIZED \\
\hline Responsiveness & $\begin{array}{l}\text { Scone: }-1 \\
\text { Access indirect; delay in } \\
\text { response to user } \\
\text { requests due to varied } \\
\text { requests, documentation } \\
\text { time }\end{array}$ & $\begin{array}{l}\text { Score: } 0 \\
\text { May be favorable; } \\
\text { somewhat limited by } \\
\text { need to translate or } \\
\text { transfer data between } \\
\text { distributed systems }\end{array}$ & $\begin{array}{l}\text { Score: } 1 \\
\text { Favorable; data and } \\
\text { functions exist on } \\
\text { closely defined systern }\end{array}$ \\
\hline Reliability & $\begin{array}{l}\text { Score: }-1 \\
\text { Too many variations of } \\
\text { essential data processing } \\
\text { steps to generate } \\
\text { repeatable products }\end{array}$ & $\begin{array}{l}\text { Score: } 0 \\
\text { May be favorable (see } \\
\text { above); standards must } \\
\text { also be philosophically } \\
\text { similar }\end{array}$ & $\begin{array}{l}\text { Score: } 1 \\
\text { High reliability; data } \\
\text { processing simplified }\end{array}$ \\
\hline $\begin{array}{l}\text { Optimum } \\
\text { Functionality }\end{array}$ & $\begin{array}{l}\text { Score: }-1 \\
\text { Too much effort to } \\
\text { establish; consistency, } \\
\text { documentation of } \\
\text { products, operations a } \\
\text { challenge }\end{array}$ & $\begin{array}{l}\text { Score: } 0 \\
\text { May be favorable (see } \\
\text { above); other functions } \\
\text { sh suld be the same as } \\
\text { centralized option }\end{array}$ & $\begin{array}{l}\text { Score: } 1 \\
\text { Favorable without } \\
\text { extensive effort; } \\
\text { unified systems and } \\
\text { applications } \\
\text { environment }\end{array}$ \\
\hline $\begin{array}{l}\text { Implementation and } \\
\text { Operation }\end{array}$ & $\begin{array}{l}\text { Score: }-1 \\
\text { Implementation of } \\
\text { standards among diverse } \\
\text { systems nearly } \\
\text { impossible; difficult to } \\
\text { maintain operations }\end{array}$ & $\begin{array}{l}\text { Score: } 0 \\
\text { Dependent on } \\
\text { development. of data } \\
\text { interfaces; custom data } \\
\text { interfaces could require } \\
\text { substantial maintenance }\end{array}$ & $\begin{array}{l}\text { Score: } 0 \\
\text { Implementation will } \\
\text { be significant; } \\
\text { maintenance } \\
\text { simplified by well- } \\
\text { defined system }\end{array}$ \\
\hline $\begin{array}{l}\text { Unresolved } \\
\text { Limitations and } \\
\text { Problems }\end{array}$ & $\begin{array}{l}\text { Score: }-1 \\
\text { Timeliness and control } \\
\text { of data, data products a } \\
\text { continual problem }\end{array}$ & $\begin{array}{l}\text { Score: } 1 \\
\text { Complete accessibility } \\
\text { of distributed data } \\
\text { likely to be a continual } \\
\text { problem; avoiding } \\
\text { duplicate data and } \\
\text { inconsistency in data } \\
\text { documentation also } \\
\text { problematic }\end{array}$ & $\begin{array}{l}\text { Score: } 0 \\
\text { Acquiring and } \\
\text { establishing required } \\
\text { resources (hardware } \\
\text { and software) the } \\
\text { greatest challenge }\end{array}$ \\
\hline Total Score & -5 & 1 & 3 \\
\hline
\end{tabular}

The following scoring system was used to compare alternatives: 1 = favorable conformance; $0=$ neutral/intermediate conformance; and $-1=$ unfavorable conformance.

The results indicate that the centralized system alternative will have slightly better performance than the distributed system. The performance of the distributed system is dependent on the ability to implement data access and translation capability. The general structure of the request/referral system is too diverse for it to provide needed performance for OREIS. 


\section{SELECTION OF ALTERNATIVE}

The preferred alternative for OREIS is a well-defined, stable, centralized system. It is a system in which all the steps of data management and data product generation are traceable and documented. The system should be able to accomplish these tasks in an integrated computing environment so that comprehensiveness and consistency in the data and documentation can be maintained.

The form of the centralized system for OREIS, however, will not be a large, single mainframe configuration. Any number of CPUs and storage devices may be employed to provide the necessary capacity for the system. The user will log into a central system that transparently accesses a single version of the data with data base and communications tools over network interfaces. Portions of the data and software may be located on workstations or a data server. Additionally, the system will use a series of workstations placed at dedicated user locations. Each workstation can provide its own local processing. This configuration will overcome limitations in availability and reliability that can occur in traditional central systems. Intermittent users of OREIS will access it via network communications. Users located at remote sites (e.g., Paducah, Portsmouth, and some ER subcontractor locations) may use stand-alone clones of the central system for data processing activities. These clones would have identical software and data base configurations to the central system so that information could be transferred to them wihout modification or translation.

The centralized system is the only alternative that is likely to attain the performance fealures required for OREIS (e.g., consistency and reliability). The request/referral and distributed systems are not likely to attain the degree of certainty required by OREIS because of the diversity of actions possible with these alternatives. The centralized system is the only alternative that conceptually supports the need for a single version of the data to avoid ambiguity. 
PART II: SYSTEM REQUIREMENTS DEFINITION 


\section{PURPOSE}

The purpose of the System Requirements Definition is to document all of the components of the OREIS system and their intended interaction. A requirements definition is used by system developers and users to clearly state the minimum specificaticns required by the system and to establish a consensus on system operation and use.

OREIS must be able to show conformance to the following six constraints: standardization, documentation, robustness, integration, reliability, and predictability. These constraints led to the selection of a centralized system. Because the centralized system was selected, the issue of user needs were further addressed. The survey respondents did not rank user interface, remote access, or access to a centralized data base as highly as they ranked some other features of a system. These three features, however, are essential to the usability of a centralized system and were added to the requirements.

The sections of the Requirements Definition document cover the following topics:

- Section 12-Definitions of OREIS-specific terminology and descriptions of roles of various organizations that are an integral part of OREIS.

- Section 13-A master list of the requirements defined for OREIS.

- Section 14-A description of OREIS users, their data needs and expected uses.

- Section 15-A description of data sources, data types, and the process for interaction between data generators and OREIS.

- Section 16-A definition of system outputs.

- Section 17-A description of system requirements, including security, quality, hardware, software, and programming requirements.

- Section 18-A description of performance criteria required by the system.

- Section 19-A listing of unresolved issues pertaining to system requirements. 


\section{DEFINITIONS}

\section{Applicable or Relevant and Appropriate Requirement (ARAR)-}

ARARs are any health-based or regulatory guideline values that might be used to evaluate environmental data. ARARs exist for several media (air, water, soil, and food) and are appropriate for some types of environmental restoration work.

\section{Characterization data-}

Field and laboratory measurements of physical and chemical parameters that characterize the nature and content of a sampling location; for example, depth-to-water, $\mathrm{pH}$, and chemical analyses.

\section{Data custodians-}

Persons appointed within environmental programs that are responsible for the care and maintenance of the data and serve as the interface between data generators and OREIS. These individuals authorize changes and updates to OREIS data and also are the persons to contact if questions arise concerning OREIS data. In some programs, these individuals may be the data generators; in other programs, they may be the data base managers.

\section{Data base administrator-}

Person responsible for the integrity of the OREIS data base. Duties include implementation of system design, security, and back-up procedures and updating system components to maintain an efficient and secure system.

\section{Data generators-}

Persons within environmental programs who initiate the sampling or construction activities that create data and are the sources of data residing in OREIS. These individuals authorize the release of data to OREIS when they are satisfied that the data are complete.

\section{Data owners-}

A confusing term referring to the individuals or environmental programs that originally were responsible for data collection. All environmental data collected for Energy Systems' Environmental Monitoring and Environmental Restoration programs are the property of the U.S. Department of Energy. Individuals within environmental programs collect data and may be responsible for the care and maintenance of data (see data custodians), but they do not own data.

\section{Environmental Monitoring (EM)-}

Refers to staff and activities associated with current compliance monitoring of groundwater, surface water (NPDES data), biota, and other media. Includes managers, technical staff, data managers, groundwater coordinators, and subcontractors working on EM projects. 


\section{Environmental Restoration (ER)-}

Refers to staff and activities associated with remedial investigations and cleanup of radioactive and hazardous wastes and, potentially, other contaminants. Includes managers, technical staff, data managers, risk assessors, and subcontractors working on ER projects.

EPA Interchange File Format (IFF)-

A comma-delimited ASCII file format established by EPA-Region IV, for the transfer of electronic data.

\section{Historical data-}

Any environmental data collected before the OREIS start date.

\section{Maximum Contaminant Level (MCL)-}

Regulatory standards for water. Used to determine if water data exceed regulatory limits.

\section{Metadata-}

Information available about an entity or event within the data base. It may be handled as data by the data base management system.

\section{OREIS product-}

The result of any form of data retrieval from OREIS. The defined product types are tabular reports, statistics, graphs, maps, and electronic subsets of data.

\section{OREIS user-}

Anyone needing an OREIS product. Users may (1) have access to OREIS and retrieve data or data products directly, (2) request processed data from OREIS, or (3) request data products to support reporting requirements.

\section{Request system-}

Some OREIS users will retrieve OREIS data or data products through a written request system. The request describes the data and data format required by the user. An OREIS staff member will process the request and deliver the product to the user. A procedure will be written that describes the details of the request system. 


\section{REQUIREMENTS}

The following is a master list of the major requirements of OREIS. Detailed discussion of each of these requirements are organized by topic in Sections 14-18 of this document.

- System Users

Users will either submit written requests for data from the system or will apply for online access to OREIS (Sect. 14). A user profile will be established for everyone granted online access to OREIS (Sect. 17.1). Online users must be able to access OREIS from remote locations (Sect. 17.3).

- Data Inputs

OREIS will store and retrieve environmental data from several sources (Sect. 15.0). OREIS must be flexible and adaptable enough to work with the individual data sources (Sect. 15.1). OREIS must store and maintain a diversity of data (Sect. 15.2). OREIS must import data submitted electronically into the production data base (Sect. 15.3). Data custodians will be supplied with data input programs for data types not currently available in electronic format (Sect. 15.3). The history of each value in the data base must be documentable (Sect. 15.4). Changes to or deletions of data must be documentable and controlled (Sect. 15.4).

- Data Outputs

OREIS must be able to provide users with a variety of consistent and dependable products (Sect. 16.0). Products from OREIS must be documented by the system (Sect. 16.1). OREIS must have a means of exporting data for use on other systems (Sect. 16.1.2).

- Product Capabilities

OREIS should include the following product capabilities: (1) a facility for programmers to automate the generation of standard reports; (2) production of graphics (charts and plots) for reports, presentations, and scientific analysis; (3) procedures for generating simple statistics and complex statistics for scientific analyses and hypothesis testing; and (4) generation of maps whose contents are fully specified by OREIS users (Sect. 16.1.1).

- User Interface

OREIS must have an easy to use and friendly interface system that supports all users (Sect. 16.2). All the menu screens must provide helpful information (Sect. 16.2.1). Users must be allowed to narrow and subset the data in the OREIS product being generated (Sect. 16.2.2). Data subsetting should be similar for all OREIS products (Sect. 16.2.1). OREIS must enable users to save a data query definition for use at a later time (Sect. 16.2.4). Users with proper experience and access capability will have greater flexibility (Sect. 16.2.5). 
- System Requirements

OREIS must be capable of maintaining comprehensive data security (Sect. 17.1) and data quality standards (Sect. 17.2). The OREIS design should minimize the opportunity for duplicate (or nearly duplicate) copies of the data (Sect. 17.2). The development process will consider the following criteria: (1) integration of as many functions as possible within a common data applications environment, (2) compatibility and consistency between the components of the OREIS, (3) automation of the highest-level tools (e.g., menu language) for a controlled user interface, and (4) avoidance of "patches" to achieve the desired internal compatibility within its components (Sect. 17.4). OREIS must develop standards for data entry, editing, documentation, QA, formatting, storage, and reporting (Sect. 17.5).

- Performance Criteria

OREIS must have the hardware and the software licenses to support several concurrent online users (Sect. 18.0). OREIS must have the capacity to store several gigabytes of data and provide timely response to users (Sect. 18.0). OREIS must have access to the hardware necessary to produce quality maps (Sect. 18.0). 


\section{SYSTEM USERS}

- User Access-Users will either submit written requests for data or data products from the system or will apply for online access to OREIS for direct query of the data.

Both online and offline OREIS users will have a variety of data needs. The users will differ in (1) the input sources that they will access, (2) the specific data types that they will want, (3) the types of products that they will require, (4) the level of detail that they will retrieve, and (5) the equipment they use to access the system. Three major user groups are broadly categorized as environmental restoration users, environmental monitoring users, and other users.

\subsection{ENVIRONMENTAL RESTORATION}

The impetus for OREIS is to support ER activities at OR facilities. A number of different users are part of the ER process and are listed in Table 7. Data custodians for each ER project who supply data to OREIS must have access to OREIS to review and initiate changes to their data. ER managers and technical staff who perform ad hoc reports and who will be the contact point for any data distributed to subcontractors and other groups working for ER also will require access to OREIS. These users will probably be intermittent users of the system and will require a system that is easy to use, including menu screens that provide step-by-step instructions.

ER report preparation teams who require standardized products will likely be more frequent users of the system. The RI/FS and RFI reports produced by these groups are prepared over many months, and these groups may be preparing several reports concurrently. This user group needs a convenient means of saving and retrieving query specifications used in earlier versions of the report as a means of producing consistent documents. This group also needs the ability to produce several OREIS products all based on the same subset of data, especially tabular reports and maps.

ER subcontractors will have a variety of OREIS data needs depending on the services that they provide to ER programs at Energy Systems or OR. Their needs have not been explicitly defined, but it is expected that intermittent offline access will be required. Access to OREIS data by subcontractors will be coordinated by their contacts within the OR and Energy Systems' ER programs.

ER personnel at OR will require online access to OREIS to review electronic data and documents submitted to EPA and to help address questions that may arise during a document review process. Additionally, OR can use online access to assist in ER program oversight, including monitoring and auditing of site activities. OR will have access to data that is quality assured. 


\begin{tabular}{|c|c|c|c|c|c|}
\hline 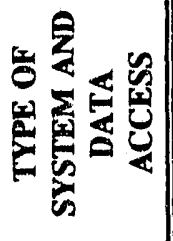 & 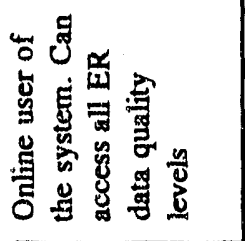 & 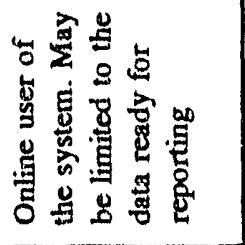 & 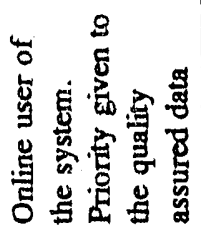 & 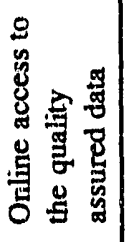 & 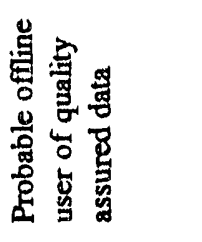 \\
\hline 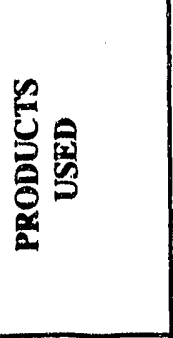 & 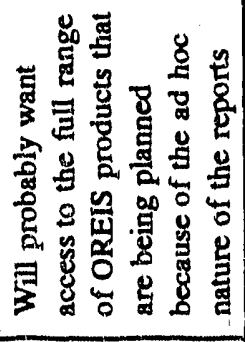 & 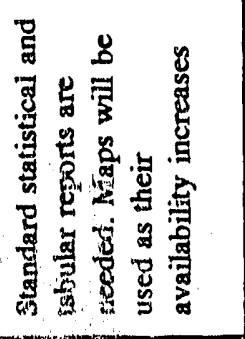 & 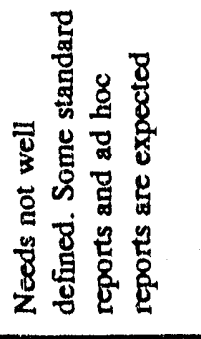 & 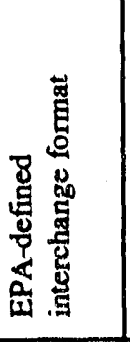 & 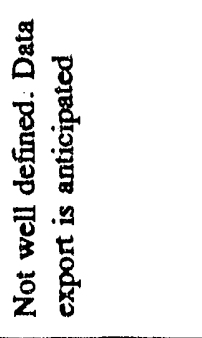 \\
\hline $\begin{array}{l}\frac{n}{2} \\
\frac{1}{2} \\
\frac{1}{2}\end{array}$ & 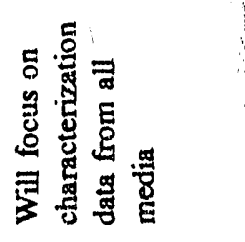 & 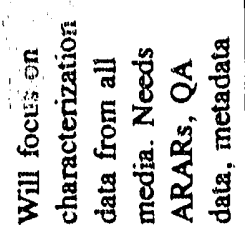 & 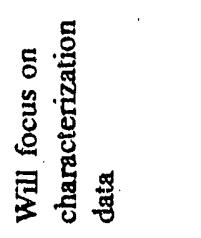 & 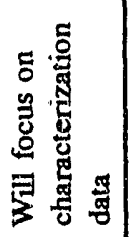 & 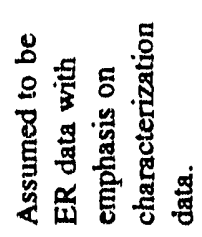 \\
\hline 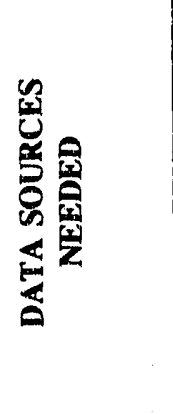 & 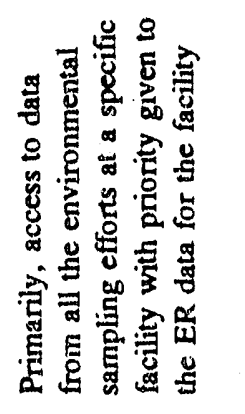 & 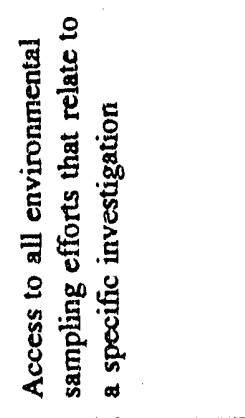 & 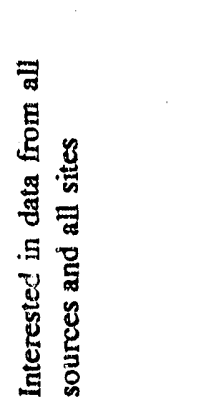 & 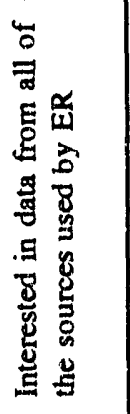 & \\
\hline 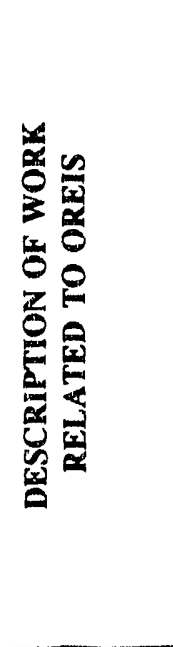 & 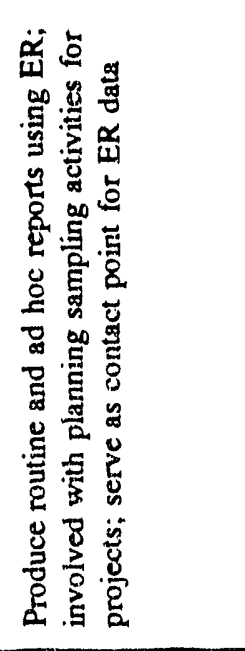 & 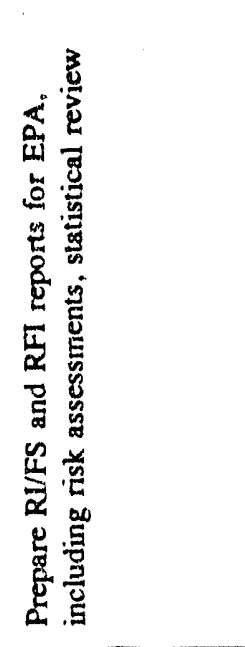 & 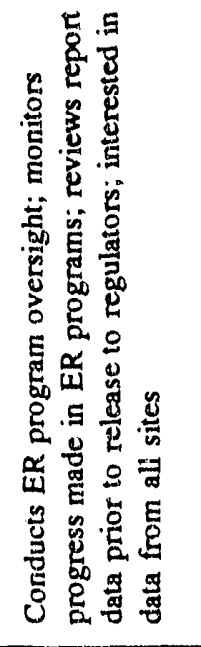 & 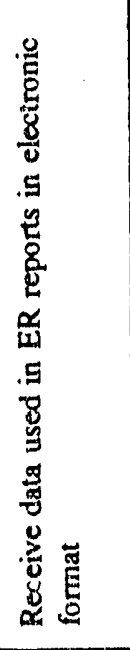 & \\
\hline 福 & 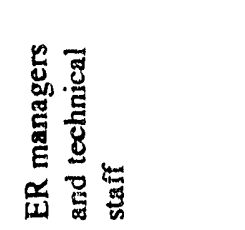 & 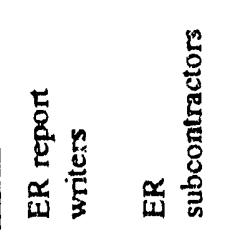 & 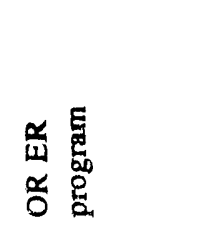 & 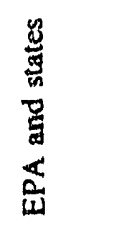 & 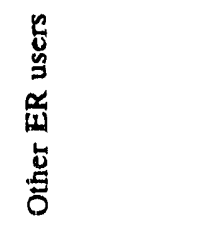 \\
\hline
\end{tabular}


EPA and states personnel are designated ER users due to the FFA stipulation requiring that electronic copies of report data be supplied to these users. A procedure will be written that dictates who will produce these copies, when they are created, how they are delivered, and the naming convention used to link hard-copy reports to the electronic version. Electronic data will be tranmitted to EPA using the EPA-defined interchange file format.

\subsection{ENVIRONMENTAL MONITORING}

The FFA requirement mandates that data generated by environmental monitoring be a part of OREIS. Because EM data will be in OREIS, individuals from EM programs may choose to be users of OREIS. Most environmental monitoring programs have well-established data management practices and data quality goals that meet the needs of their programs, but access to the data is often fairly limited to other staff. They may choose to use OREIS to supplement the current data management activities by making data more easily available to a wider audience.

The potential users from EM are listed in Table 8. EM data custodians who supply data to OREIS must have access to OREIS to review and initiate changes to their data. EM managers and technical staff have data needs similar to those described for ER managers and technical staff. The primary differences will be in the scope of the data of interest. ER focuses on all available data for a specific geographic area under investigation, while EM focuses on sampling data for a current time period and a specific medium. Because both programs will be executing ad hoc queries, the difference should not impact the development of a flexible query system.

Groundwater coordinators who use OREIS will have more interest in well construction data and the MCL portion of the ARARs than will most of the other EM user groups; access to mapping products will also be needed. EM subcontractors who use OREIS will have needs similar to those of ER subcontractors. Standard products needed to accommodate EM-specific reporting will be incorporated into OREIS as needed.

\subsection{OTHER USERS}

Data access will eventually be expanded to include other OR and Energy Systems users. The reporting, graphing, and mapping capabilities of OREIS should be robust enough to support the needs of other Energy Systems' programs and their subcontractors. For example, OREIS will support the administrative record by distributing information to citizen groups and also will provide data to ATSDR for its use in preparing human health effects studies as required by law. Initially, users who are not directly associated with ER or EM may access OREIS data through the written request system. 
32

\begin{tabular}{|c|c|c|c|c|c|}
\hline 敋象象 & 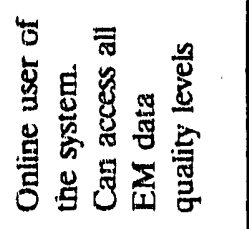 & 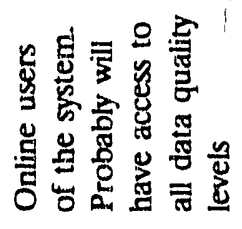 & 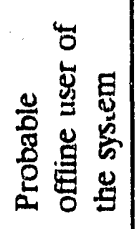 & 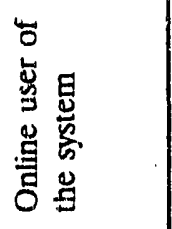 & 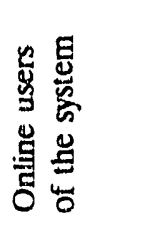 \\
\hline $\begin{array}{l}0 \\
0 \\
0 \\
0\end{array}$ & 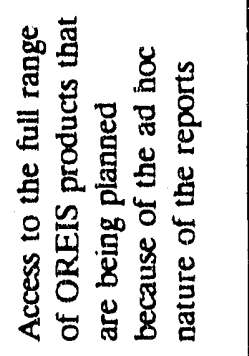 & 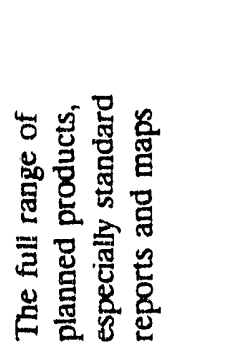 & 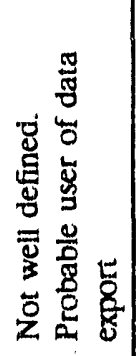 & 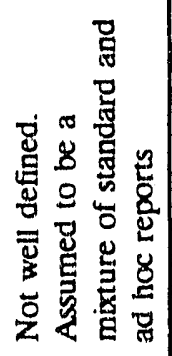 & 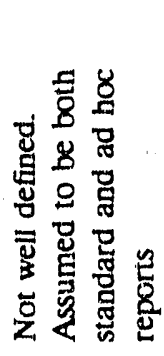 \\
\hline 视 & 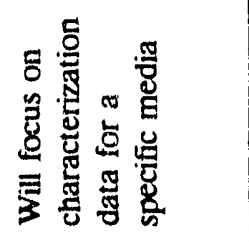 & 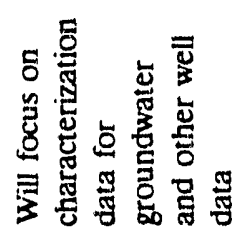 & 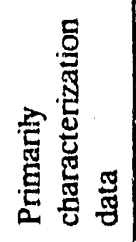 & 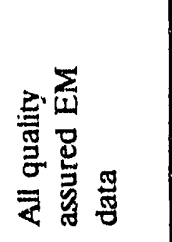 & 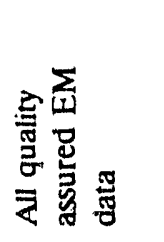 \\
\hline 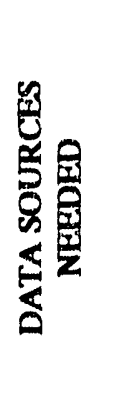 & 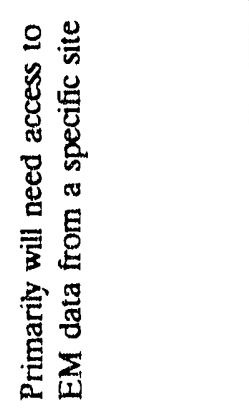 & 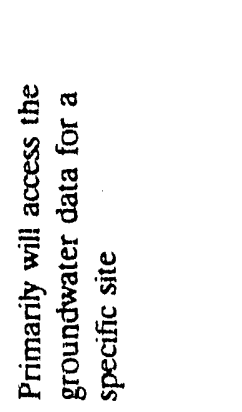 & 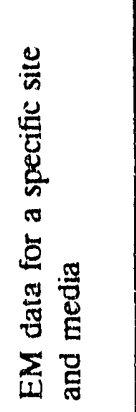 & & 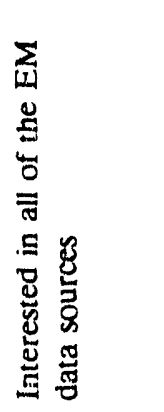 \\
\hline 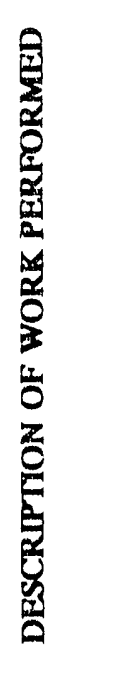 & 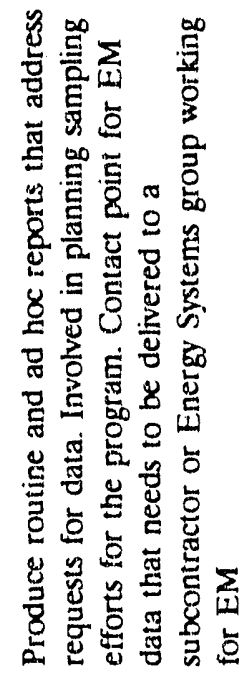 & 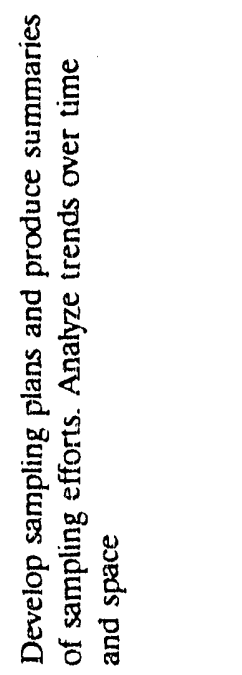 & 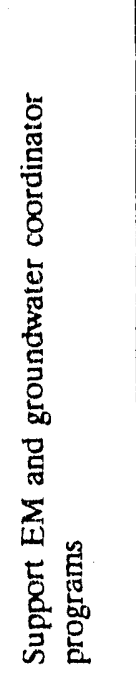 & 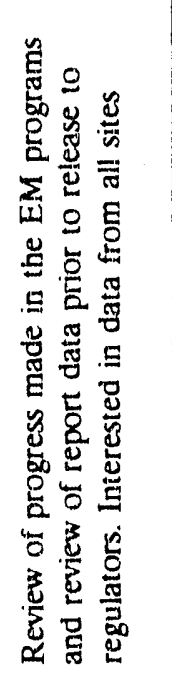 & 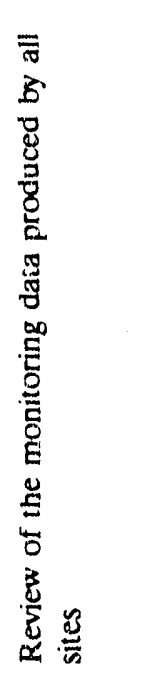 \\
\hline 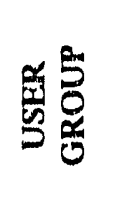 & 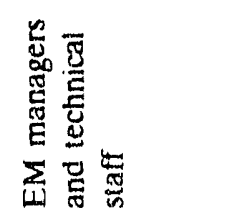 & 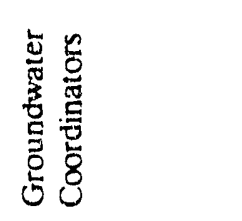 & 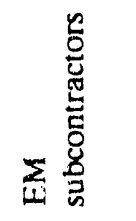 & 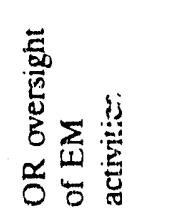 & 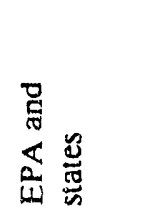 \\
\hline
\end{tabular}




\section{DATA INPUTS}

- Date Storage/Retrieval-OREIS should systematically store (QA and document) and retrieve (extract for OREIS applications) environmental data in many combinations and subsets. Environmental data can come from several sources and involves several types of data.

\subsection{SOURCES OF ENVIRONMENTAL DATA}

Data from ER and EM programs will form the basis of the OREIS. There may be a mixture of program managers, technical staff, and data base managers that will be involved in providing data to OREIS, and the individual sites may each choose to interact with OREIS differently.

- Integrate Varied Data Sources-OREIS needs to be flexible and adaptable enough to work with the individual data sources.

Within each environmental program, there are several sources of data that must be brought together for OREIS. For example, data come from analytical laboratories, field samplers, and well drillers, and these sources change over time. To ensure that OREIS staff has clear lines of communication and to minimize the impacts on existing programs, environmental programs at each site will appoint a contact person for all of their data.

\subsection{REQUIRED DATA TYPES}

- Data Types-OREIS must store and maintain the diversity of data currently needed for ER.

\subsubsection{Characterization Data}

The initial OREIS data base will be an integration of the characterization and supporting data collected by site ER and EM programs. This combination of different, although somewhat similar, data structures will make it difficult to develop a single structure that will be acceptable to all users. A prototype system will be developed to assist the users in refining the data requirements that are essential to the users of OREIS.

The current system emphasizes the use of characterization data. Characterization data are measurements associated with sampling events. They can originate in the field or in the laboratory and can measure chemical or radiological content or physical parameters. These samples can be from many media including soil, groundwater, surface water, sediments, air, biota, or sludge. The analytical results are expected to already be in an electronic format. Conversion routines will need to be written for each of the sources.

Supporting data include sample log sheets, instrument calibration log data, well construction parameters, borehole locations, and storage tanks. These sources of data may be 
available only in hard-copy format and may have been maintained in a variety of forms. These data sources need to be entered into or indexed in OREIS.

Historical data will be included in OREIS as the need arises (i.e., all data used in ER reports must be in OREIS). Generally, the addition of historical data will start with the most recent and work towards the oldest. Data will be included only as long as the data quality can be assessed and is sufficient to make the data useful.

\subsection{Metadata}

Access to metadata will be important feature of OREIS. Metadata are data about an entity or result within the data base; they provide background information on the source of the data and on the comments attached to the data. Metadata will be accessible to online OREIS users to provide query assistance and to help users make informed decisions about the use of the data. Work is ongoing to define the types of metadata that will be available at every level, the text of the metadata, the sources of metadata, when metadata are appropriate, $\therefore$ d how the metadata will be collected. Examples of metadata are the location of associated documents, such as the sampling and analysis plan, and contact information on data custodians.

\subsection{INPUT FORMAT}

- Data Impont Fonnal-Mosi data will be submitted to OREIS in electronic format. OREIS must be able to import these data for review and for incorporation into the production data base.

- Data Import Support-OREIS developers will provide data custodians with data input programs for all data types not currently available in electronic format.

Transmitting data to OREIS will evolve from accepting what is currently available in hard-copy or electronic forms to eventually reaching a level in which most data are transferred to OREIS in electronic standard formats. Data input programs will be developed to assist data generators or custodians to provide electronic data in a standardized format. The input programs will be developed in an easy-to-distribute format for data generators or custodians and will be executable on existing hardware

Initially, data available in electronic format will be supplied to OREIS in the form most familiar to the user and then converted to the OREIS format by OREIS staff. OREIS procedures will specify the needed variables and their definitions and indicators for key tields, and specify the documentation and metadata that must accompany each transmittal. 


\subsection{DATA TRACKING}

- Data Tracking-OREIS must contain procedures and software checks that control, track, and document the history of each value in the data base.

Data import into OREIS and the subsequent change or deletion of any value must occur in a controlled and documented environment. OREIS staff will be responsible for importing the data into the OREIS. The original copy of the data submitted to OREIS will not be altered and will be stored indefinitely in case of an error in converting data to the OREIS format. All data will be reviewed for completeness and correctness before being added to the production version of the data. Documentation will be maintained on each set of data submitted for inclusion into OREIS.

- Changes and Deletions-Changes to or deletions of data in the production system can only be implemented through a change request procedure to ensure documentation of data values. A change request can be submitted in either written or electronic format.

Designated data custodians will be the only individuals authorized to change or delete data values. Custodians can either submit a change request in writing or can use the menu system to submit an electronic change request. All changes and deletions will be appended to a change log. A system batch program will implement the changes on a scheduled basis.

\subsection{RESPONSIBILITIES}

Data custodians will be the contacts for all data and data changes coming into OREIS from their site and will be the contacts for OREIS users who need more information about the data. Custodians authorize all additions, changes, or updates to the data under their supervision. Custodians are also the point of contact for OREIS staff who have ques.ions concerning data values, $\mathrm{QA}$, or sampling procedures.

Custodians will be expected to review the data for completeness and to ensure that the variables for the data scurce are properly mapped into OREIS variables. Procedures will be developed to guide the review process. The OREIS data base administrator will be responsible for responding to any questions concerning OREIS data requirements, definitions, and relationships. Custodians will also be responsible for the metadata or documentation that must be submitted with data transfers. Procedures will be written to specify the relationship between OREIS and data custodians at each site and within each program. The procedure will include guidelines on transfer documentation, data submission procedures, data changes, and user requests for information in OREIS. 


\section{DATA OUTPUTS}

- Versatile Products-OREIS must be able to provide users with a variety of consistent and dependable products.

An overview of the functional components and product applications that need to be incorporated into OREIS is presented in Figure 1.

\subsection{PRODUCT REQUIREMENTS}

Product Documentation-Standard OREIS products must be documented by the system.

All queries, printed reports, maps, and supported downloads must include documentation describing the subset of data and the date retrieved. The documentation should be complete enough to explain differences between reports that are nearly identical in appearance.

\subsubsection{Hard-copy Products}

The initial list of standardized reports, graphs, and maps will be derived from the needs of ER and groundwater program coordinators. The number of standardized formats for hardcopy products will be expanded over time to meet more needs of the users. The system must incorporate conversions or calculations that are widely used in reporting (e.g., a choice for handling detection limits when performing statistics). The required products include:

- Report generation-OREIS should include a capability for programmers to automate the generation of standard reports. This report generation capability should also readily allow for the adaptation of existing reports for new reporting requirements.

- Graphics-OREIS should produce graphics (charts and plots) for reports, presentations, and scientific analysis. These graphics may include either 2-D or 3-D representations and should be interfaced with statistical summarizations and analyses and maps.

- Statistics-OREIS should have procedures for generating simple statistics for reporting (e.g., mean, sum, min, and max) and complex statistics for scientific analyses and hypothesis testing.

- Mapping and spatial analysis-OREIS should generate maps according to a standard map format. The system should also manage digital data, display maps electronically, and provide spatial processing and analysis of geographic data. The spatial extent and location of environmental measurements are essential for accurate interpretation of ER data. 
UHNL UWH. $91 M$ M 1030 S

\section{System Design: Functional Components of OREIS}

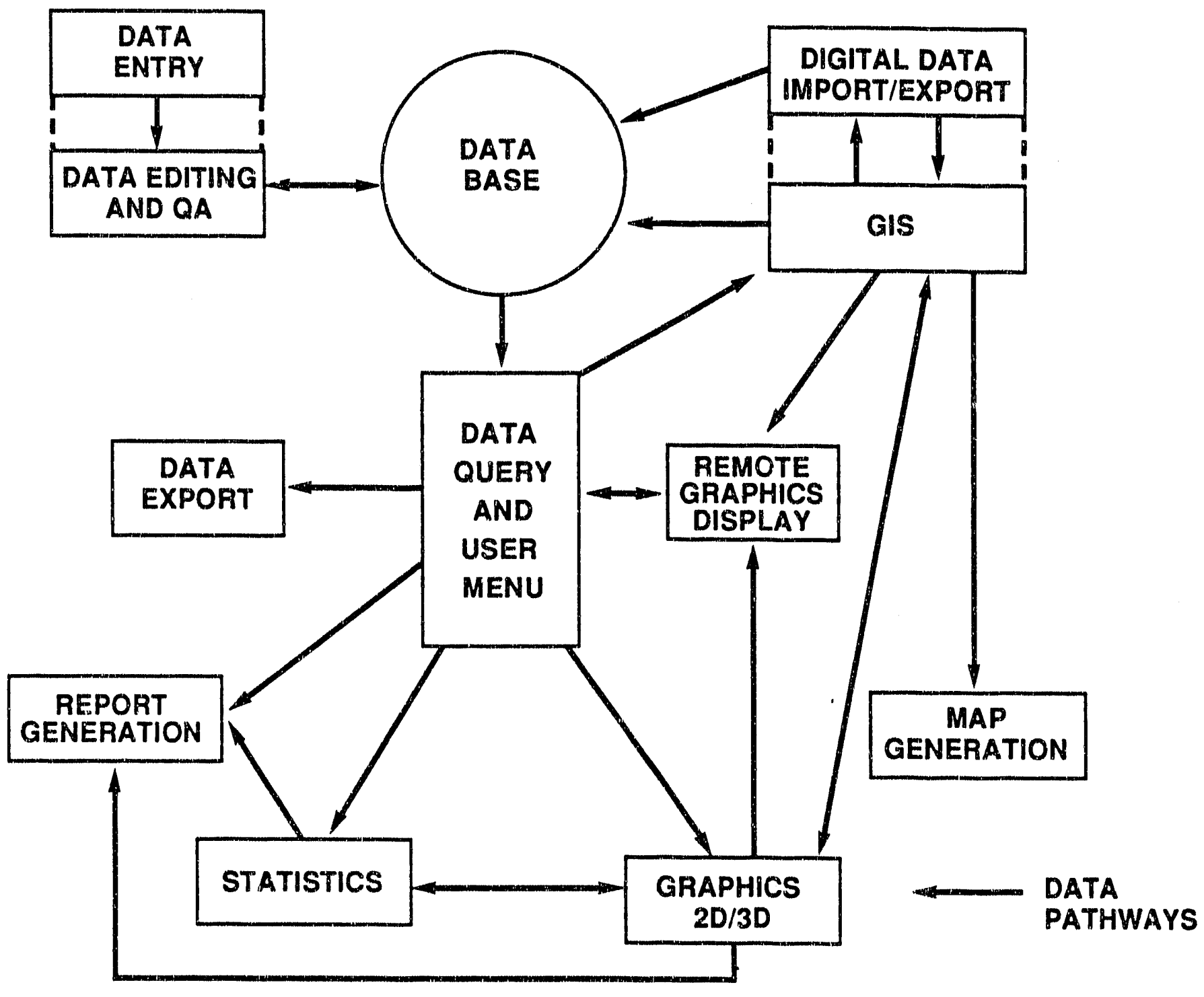

Fig. 1. System design: functional components of OREIS 


\subsubsection{Electronic Output}

Documentation of data export is as important as the data itself; export data must contain appropriate documentation. The two uses of data export are transmission of electronic copies to (1) regulatory agencies and (2) system users. Data transmitted to regulatory agencies will be in a specific and documented format agreed to by all parties. OREIS must have the ability to generate electronic copies of data for the states and EPA in a consistent, documented, and uniform manner. The media used may be floppy disks, tapes, or other media that are acceptable to the receiving agency. OREIS must also export data to users' own systems for their own use.

\section{- Data Export-OREIS must have a means of exporting data to use is in a documented format (e.g., WK1, DBF, and SSD format.)}

OREIS will support well-recognized export data formats used by commercially available software programs. The initial list of supported software export protocols is expected to include, at a minimum, a data base format such as dBase (DBF), a spreadsheet format such as Lotus (WK1), and a graphical interchange format such as PCX or DXF. Subsets of the data will also be available in the native format of the OREIS component software (e.g., ORACLE, SAS, and ARC/INFO). The list of supported software will expand with time as users express preferences. Export to ASCII files will be supported but will be the protocol of last choice because of the increased opportunities for data corruption. OREIS-supported export will have accompanying documentation that describes the subset of data that was exported. For example, the number of records and the minimum/maximum or frequency of values of the data transferred might be appropriate documentation for some types of data. Users will then be responsible for checking the documentation to ensure that the data were exported intact. In addition, users connected from remote locations may be required to use specified data transfer protocols in order to ensure data quality. An example transfer protocol is Kermit. Users will be able to export to the media of their choice available at their facility.

\subsection{USER INTERFACE/QUERY SYSTEM}

\section{- User-friendly Interface--OREIS must have an easy-to-use and friendly interface system that supports both intermittent and experienced users.}

Menus significantly increase the reliability and consistency of the system's response by controlling user interaction with the system to definable, traceable, and correct (although not necessarily logical) sets of choices. The availability of high-level tools for modifying and developing menus contributes to the reliability of the system by automating the documentation and development of predictable methods. Because menus are not efficient for advanced users and can interfere with execution of complicated commands, the user interface should also include a command language for advanced users. 


\subsubsection{Menu System}

OREIS should include a fairly complete menu system for its user interface. This will minimize the requirements for user training and support and will encourage use of the system by the intermittent user. The interface also provides a means of controlling and documenting the interactions between the system and the user. This feature will increase the likelihood that system products will withstand audits and reviews.

- Menu Requirements-Menu screens in OREIS must (1) remind users of the menu path they have taken and (2) give instructions on what is expected of the user.

Screens must be informative and assist users. Intermittent and new users should feel comfortable using the system without assistance.

\section{- GIS Menus--Query screens for all OREIS products should have the same "look and feel."}

User menu screens for maps have options that are unique to the mapping environment. To the extent possible, the user interface for all products, whether they be tabular reports or maps, should have similar data subsetting screens, common terminology, and the same "look and feel."

\subsubsection{Narrowing the Query}

- Queries-The user must have menu options that narrow and subset the data to be included in the product being generated.

Narrowing the query can include the selection of (1) a site, environmental category, sampling location, well, borehole, tanks, or other identifier; (2) a time frame that depends on the context; (3) an analyte or groups of analytes; (4) detected analytes; (5) analytes above a health or environmental standard; (6) a data quality flag; and (7) individual samples.

\subsubsection{Online Help for Users}

The user query system will be supported by a variety of sensitive online help screens. In addition to on-screen directions that prompt the user, a designated keystroke or menu selection will activate a system help window. The system help window will provide the user with information on other available keystrokes, system use, and screen acronyms. Another designated keystroke or menu selection will provide the user with a context-sensitive data dictionary. The data dictionary will provide users with descriptions of variables and a list of valid values. This will assist users who are unfamiliar with some of the variables used to refine queries. Another keystroke or menu selection item will access metadata. 


\subsection{User Options}

- Saving Queries-OREIS must enable users to save a data query definition for use at a later time.

Saving reports can be used to establish report formats that are used repetitively or to save a working session to be resumed later. Users should be able to select a subset of data for one OREIS product and save the query so it can be used for another application. Handling of saved queries should also be similar to that of data elements so that they can be cataloged, sorted, tabulated, and copied. The system must maintain a log of users and their use of data types. Data custodians will be able to request a report on the usage of their data.

- User Customization-Users vith proper access capability will be able to write their own programs and will be able to create supplementary data files that augment OREIS.

Users having sufficient proficiency of OREIS applications software may write their own programs. Software proficiency includes a demonstrated ability to develop, document, and ensure the quality of special procedures. Procedures will be written for granting this access capability. 


\section{SYSTEM REQUIREMENTS}

\subsection{SECURTYY REQUIREMENTS}

Access to OREIS will be limited. Online data access will be limited to authorized users with proper access authority for the requested data. Hardware and software devices of the users may sometimes pose restrictions.

\section{- User Profile-A user profile will be established for each OREIS user.}

A user profile will include any data/system access restrictions that might apply. Restrictions are necessary to satisfy quality and security objectives. To ensure data security, only specified users can make changes to the data. To ensure data quality and its defensibility, only users with special training and preparation cin develop customized programs and supplementary files. Users external to Energy Systems and OR will be limited to access to data with the highest levels of data validation and confidence.

The issue of incorporating classified or sensitive data into OREIS has not been fully explored. It is recognized that a fully operational system will probably include classified or sensitive data; alternatives for handling such data are being considered. It is anticipated that all data used in reports to the regulators will be in an unclassified form and therefore readily available from OREIS.

\subsection{QUALITY REQUTREMENTS}

- Quality Standands-OREIS must be capable of maintaining comprehensive data quality standards.

Data quality is defined as data and data products that are reliable, predictable, traceable, replicable, and in a common format. Attention to data quality must begin at the data source; ideally, a data audit trail from sampling through reporting should exist that would include a complete description of the data's origin, processing steps, and use. Realistically, current data audit trails will contain gaps. When incomplete audit trails of data exist, gaps in the data should be reflected by the use of quality assurance flags or by metadata that describe the weaknesses of the data. Procedures will be required to ensure improved data quality standards throughout the life cycle of the data.

Existing environmental data base systems often assume that characterization data are the only data type in which attention to quality and traceability are important. OREIS will apply quality standards to all data sources. All data in OREIS must be of a known and definable quality, and the appropriate quality disclaimers must be available.

- Multiple Copies-OREIS design should minimize the opportuni.y for duplicate (or nearly duplicate) copies of data. Multiple copies of data offer frequent opportunities for storing (and reporting) inconsistent and/or ambiguous results. 
All applications run on OREIS must access a single version of the data base. Although multiple copies of data will exist, e.g., backup copies and copies on stand-alone clones in remote locations, OREIS must be designed to minimize inconsistency problems that can be created from using data from multiple copies. Procedures, such as check sums, will be used to determine if changes have occurred.

\subsection{HARDWARE AND SOFTWARE REQUIREMENTS}

OREIS must be developed using commercially available software and must be easy for users to operate. Commercially available software speeds system development, adds stability to the system, and is often easier to maintain. OREIS will take advantage of existing hardware and software that is used by potential users of the system and will integrate existing data management practices whenever possible.

- Remote Access-The OREIS user community will consist of two groups: (1) dedicated full-time data processing staff and (2) staff from various organizations performing a wide variety of intermittent technical analyses. To support the needs of both of these groups, remote access to the data and a user interface system are functional requirements of the system.

Users will be able to access OREIS from a number of locations using a number of hardware configurations, including PCs and workstations. The features of OREIS available to users will be limited by the device used to access the data. For example, the ability to display maps on the screen will be limited to users who have hardware and software capable of graphics terminal emulation. Users having only an occasional need for map images will be able to use one of the workstations that will be dedicated to OREIS uses. The lack of local printers and plotters capable of generating graphical images may also be a limiting factor for some users. Menu interfaces for most reports and graphs should be available to remote PC users with minimal terminal emulation and cost.

\subsection{PROGRAMMING REQUIREMENTS}

OREIS is expected to be an integral part of the ER data management program for many years. It should be designed to be as flexible and upgradable as possible so that it can be revised and maintained easily. System coders should use modular design whenever possible. Help screens and menu selections should be in easy-to-revise data bases or external files instead of hard-coded programs to ensure the system is adaptable to changes. Source code should be sufficiently documented so that future revisions can be implemented smoothly. Clear and straightforward code is preferred to sophisticated schemes that only provide marginal gains in performance. System coders should minimize the use of low-level coding languages such as $\mathrm{C}$ and should avoid using ASCII files as links between system components; these should only be used when higher-level interfaces are not available.

- Integration-The design must attempt to integrate as many functions as possible within a common data applications environment. This strategy will maximize the system reliability by minimizing perilous data exchange between applications. 
- Compatibility-Compatibility and consistency between the components of the OREIS must be emphasized so that the system will require minimal development, support, and maintenance.

- Automation-Development must use the highest-level tools (e.g., menu language) for a controlled user interface. This automation will minimize the amount of "raw development" for implementation and the opportunity for errors during development and operation.

- Avoid Patches-The system could be hampered if its design includes too many "patches" to achieve the desired internal compatibility within its components (e.g., storage, analysis, graphing, mapping, and reporting facilities). A patch is a locally developed command, communications, or data translation interface that could become an implementation or operational problem if it is difficult to develop and maintain correctly.

\subsection{STANDARDS}

Standards should be developed to ensure the accuracy and clarity of OREIS data processing and products. Plans and procedures should be developed based on these standards, and the data base design should emphasize documentation of changes to the data, prevention of unauthorized data base access, data outputs that document the source of the data, and methods of obtaining information about the data.

- Develop Standards-OREIS will not be successful if it does not specify a sufficient number of standards for data entry, editing, documentation, QA, formatting, storage, and reporting. Standards should be used to ensure the accuracy and clarity of all OREIS data processing and products. 


\section{PERFORMANCE CRITERIA}

An understanding of the system requirements is important for OREIS planning because, in most cases, the optimization for one measure of performance generally results in the reduction of another. For example, efficiency in computing is generally one of the key issues in developing data base management systems. However, efficient computing is a secondary consideration compared with the reliability of the OREIS system. Overall, it is more important for the OREIS to generate "the right answer the first time" than to generate "an answer first." It is understood, however, that this statement must also be balanced with the need for system performance to be sufficiently responsive to avoid staff frustration and impatience.

The primary criterion of performance for the OREIS will be its ability to generate, support, and maintain legally defensible data. This criterion can be subdivided into two components: reliability and flexibility. OREIS must be able to perform reliably over a wide and somewhat unpredictable range of tasks.

Flexibility also directly contributes to the reliability of OREIS. If the system is sufficiently flexible, then the need for new and untested activities in OREIS will be minimized. Flexibility is very important to the OREIS user because of the diversity of data management problems and data analyses to be performed in the completion of environmental projects. OREIS users include scientists, regulators, and administrators from all aspects of environmental issues. These users will require a nearly endless mixture of environmental data, statistical procedures, graphics, and maps. Because the predictability of the specific demands for data, analyses, and reports from the OREIS system is relatively low, flexibility of the system is essential.

- Multiuser System-OREIS must have the hardware and the software licenses to support several concurrent online users, some of which will be in remote locations.

- Performance and Storage-OREIS must have the capacity to store several gigabytes of data. The system must also be able to process user requests in a timely fashion.

- Mapping Facility-OREIS must have access to the hardware necessary to produce quality maps. Many users will not have the hardware to produce their own maps and will rely on the establishment of an OREIS mapping facility. 


\section{OUTSTANDING ISSUES}

Because of the selection of the centralized system as the preferred alternative, the following issues need to be addressed further. These issues include (1) data concurrency in stand-alone clone systems, (2) provision of equipment for ER subcontractors, (3) training of users in the use of the system, (4) migration of existing data activities into the centralized system, (5) inclusion of classified or sensitive data, and (6) the establishment of coordinated standards and procedures. Both technical and administrative solutions will be required to resolve these issues.

\subsection{DATA CONCURRENCY}

The cost of high-speed network communications to remote sites (e.g., Paducah, Portsmouth, and some ER subcontractor locations) may dictate the use of stand-alone clones of the OREIS system. Because these clone systems may only have low-speed or intermittent links to the central system, they may require their own copy of the data to avoid communications bottlenecks to processing. This circumstance violates the objective of only one version of the data. The periodic distribution of data on read-only media (e.g., CDROMs) and the establishment of policies for documentation could be options for resolving this issue.

\subsection{SUBCONTRACTOR EQUIPMENT}

The centralized system assumes a minimum variation of software used for OREIS. Because subcontractors have a variety of systems, provisions for accessing the OREIS centralized system or installing a clone system must be determined and could require policy establishment and contract modifications.

\subsection{USER TRAINING}

Training and other user support is a functional requirement in establishing a functional system. Training requirements for varying levels of use need to be determined. The development of a fairly comprehensive user interface (menu and help file system and standard application programs) and user manuals are needed to provide user support. The development of standards and procedures will also enable users to use the system consistently.

\subsection{MIGRATION OF EXISTING ACTTVITIES AND DATA}

Data management activities will probably continue in their present form in each of the environmental programs for some time after the implementation of OREIS. The data management plans for individual programs and for OREIS will indicate a shared responsibility for data management. As OREIS matures, more program activities related to data management, data access, and data reporting will migrate to OREIS. Migration of any data existing activity from the program level to OREIS must be conducted using developed and 
approved procedures to ensure smooth transition. Procedures also are needed to assist in the migration of data from existing systems to OREIS.

\subsection{DATA CLASSIFICATION}

Some of the environmental data that has been collected is either sensitive or has been stored on classified machines. Classified data undergo declassification before being published in ER reports submitted to EPA. Preparing unclassified summarizations provide one available alternative for OREIS in handling classified data. Other alternatives may be required, however, to handle classified data, e.g., one CPU dedicated to OREIS use may be designated for classified or business sensitive use. Further study is needed on the potential magnitude of this need.

\subsection{STANDARDS AND PROCEDURES}

Developmental and operational standards, once developed, must be translated into usable procedures to ensure that the desired goals of reliability and consistency are communicated to all ER staff who are responsible for some portion of cradle to grave management of ER data and that these goals are met. 


\title{
APPENDIX A
}

\author{
Survey of \\ Data Management and Information Needs \\ Related to Development of the \\ Energy Systems \\ Consolidated Environmental Data Base
}

January 9, 1991 


\section{INTRODUCTION}

In response to the FFA, the ER Division of Energy Systems, in coordination with the ER Division of $O R$, is in the process of developing a consolidated data base for EM data collected at all Energy Systems' facilities. In support of this effort, we are conducting a brief survey of organizations involved in EM at Energy Systems facilities. One of the primary longterm goals of the data base is to be able to meet the data management, analysis, a id reporting needs of various EM programs. The input of future contributors and users of the data base at this developmental stage is essential to ensure that the resulting data base and user interface will meet known and projected Energy Systems needs.

The principal goal of this survey is to obtain sufficient information to determine reasonable alternatives for the development of the consolidated data base (CDB). The questionnaire is aimed at determining (1) your current data management and reporting practices and (2) jour expectations or requirements of a CDB system. The level of detail of information being sought during this planning process is intended to assist in the selection of one of three broad alternatives:

1. Request/Referral System. A request/referbal data system is a collection of data bases that is accessed, supported, and operated by specialists. These data bases may be distributed across an unlimited variety of software and hardware. The most aggregated type of information in this alternative is a data dictionary to guide specialists in their activities. Its most common means of utilization is by data specialists who can fill all of the needs for data analysis and distribution. This alternative depends on the data specialists being continually familiar with the format and status of the data needed for the CDB. User access is nonexistent for this alternative because of the dynamic complexity of the data structure.

2. Distributed Data Base. A distributed data base is similar to the "request/referral" system in that the data may be distributed across a variety of hardware and software. However, the distributed data base is limited to those systems that can provide remote and automatic access from a common user system for most of the data and analyses. Remote and automatic access means that the data can either be accessed directly through a CDB interface or the data can be automatically and electronically translated into the CDB from the distributed data base.

3. Centralized Data Base. A centralized data base would consist of a fairly restricted set of systems that contain its data. If the centralized data are distributed across more than one system, then access between the systems is fully transparent to the user. The centralized data base option would also include capabilities to perform a majority of the analyses, mapping, and report generation. 
This questionnaire is designed to answer the following general questions for planning purposes:

1. What is the diversity of the current data management practices?

(What is the heterogeneity of the current hardware and software systems? What is the accessibility of these systems?)

2. What is the general current distribution of the environmental data?

(How many different groups have the same types of data? Are the data bases segregated by environmental category or are they multidisciplinary?)

3. What is the diversity of the data needs by the CDB user?

(Are the data needs frequently multidisciplinary? Are users regularly exchanging data? Could users benefit from readily accessible data? What portion of the data needs is being handled directly by the user?)

4. What kinds of functions should the $\mathrm{CDB}$ system provide?

(Data management, QA, analyses, report generation, mapping, graphics, and GIS. Should the CDB be more than a repository that only stores and retrieves data?)

The results of this survey will be documented in a Feasibility Study report which will include an assessment of the technical and operational feasibility, benefits, and risks of each alternative. Once a preferred alternative has been identified, follow-up surveys will be conducted to assist in the specific design of the system. 


\section{SURVEY DESIGN AND PROCEDURES}

The overall purpose of the CDB and this survey was explained in the introduction. This section provides more detail on the design of the survey and how its results will be analyzed. The survey forms used for the interview of data managers and users of environmental data consists of three parts. The intent of these forms and instructions for using them are discussed in the following sections.

\section{Form 1. Contact information}

Intent. Form 1 is used to record the name, address, position, etc., of the person being interviewed as well as the name of the interviewer. This part of the survey is also a means of gathering the names of other people who might be able to contribute to this planning process.

Instructions. The appropriate responses for this form are straightforward.

\section{Form 2. Current environmental data management and reporting practices}

Intent. The environmental data management and reporting practices survey table (Form 2 ) is designed to indicate the programmatic purpose and processing activities of environmental data. It also allows tabulation of hardware, software, and accessibility of the data management systems used for each data type. Compilation of the responses will indicate the homogeneity (or heterogeneity) of the existing data management practices that will be used to evaluate the feasibility of $\mathrm{CDB}$ configuration alternatives. The information in this table is not intended to provide all of the detail necessary for the full planning and implementation of the CDB system. Follow-up surveys will be conducted to assist in the specific design of the system.

As indicated in the introduction, the general purpose to the survey is obtain an overview of current environmental data management practices at Energy Systems. There are many levels of detail that could be used to describe the current practices. In a simple approach, the survey could tabulate the number and types of environmental data sources. A detailed approach would tabulate the exact format (record structure, data set theme, variables names, etc.) and operational environment (hardware, software, and documentation) for each data base. The simple approach is not sufficient for selecting alternatives for the CDB, and the detailed approach would be impossible to tabulate for planning purposes. Therefore, the survey has been designed to provide a qualitative tabulation of categories of data activities and methods.

A qualitative response will have less interviewer bias and eliminate problems associated with converting responses into quantitative units. The qualitative responses will be evaluated in the following ways:

The degree of heterogeneity of the qualitative response will enable the $\mathrm{CDB}$ project to select one of the alternatives. 
Patterns of correspondence (coincidence) between the qualitative responses will also indicate the uniformity of the data needs of the users and potential effectiveness of the CDB design.

It is recognized that the categories of the form may generate some unclear relationships. For example, if more than one hardware/software system is indicated, it will not be possible to determine "which data and activities occur on a particular system." However, the absence of this information is not expected to interfere with the evaluation of the alternatives. After an alternative has been selected, a second interview to obtain exact descriptions for specific types of data will be necessary for implementing the CDB.

Instructions. Because the survey is intended to be qualitative, the only entry that will be required is a check mark for each applicable activity. Before entering responses into the table, the interviewer should become familiar with row and column definitions (see Attachments 1 and 2).

\section{Form 3. Evaluation of $\mathrm{CDB}$ and $\mathrm{CDB}$ GIS Functions}

Intent. The evaluation of CDB and CDB GIS functions survey table (Form 3 ) is designed to record the expectations or requirements of a consolidated data base system. The CDB must serve a variety of needs. The value of the specific functions or applications will be grouped into three general categories (i.e., essential, important, and useful), described in Attachment 3. A fourth category on the form, "not needed," is self-explanatory. The resultant Feasibility Study will evaluate both the optimum performance and implementation difficulty of each function for all $\mathrm{CDB}$ alternatives.

The required functionality of the $\mathrm{CDB}$ has a significant influence on the selection of the preferred $\mathrm{CDB}$ alternative. The best alternative for the $\mathrm{CDB}$ will be the one that performs all of its essential and most of its important functions in a well-integrated computing environment. A tendency toward a consensus about the essential and important functions should clearly dictate the requirements for the preferred $C D B$ alternative. The functions of the CDB and its GIS will be evaluated separately, except for the interrelationship between the GIS and the CDB.

Instructions. The interviewer is requested to designate one value category for each function. It is not necessary that all functions be ranked for each interview (i.e., if the contact person has no interest or knowledge of GIS applications, then these functions would not be evaluated). The interviewer should become familiar with all value and function definitions before entering responses (see Attachments 3 and 4). 
Form 1. Contact Information

Name:

Address:

Telephone:

Program affiliation:

Position:

What type of environmental monitoring program are you associated with?

Environmental Restoration Program

Compliance Monitoring

Other (specify)

Who else can provide information about your environmental data management and reporting activities?

Interview date:

Interviewer:

Comments: 
Form 2. Current environmental data management and reporting practices

ENVIRONMENTAL DATA CATEGORY

\begin{tabular}{|c|c|c|c|c|c|c|}
\hline $\begin{array}{l}\text { Data management and } \\
\text { reporting categoryb }\end{array}$ & Air & $\begin{array}{c}\text { Surface } \\
\text { water }\end{array}$ & $\begin{array}{l}\text { Ground } \\
\text { water }\end{array}$ & $\begin{array}{l}\text { Soils, } \\
\text { ctr. }\end{array}$ & Biology & Mep \\
\hline DATA PURPOSE & $* * * x * * * *$ & $* * * * * * * *$ & $* * \omega * * * *$ & $\omega * * * * * * *$ & $* * * * * * * *$ & $4 * * 4 * 4 * *$ \\
\hline \multicolumn{7}{|l|}{ Background } \\
\hline \multicolumn{7}{|l|}{ Contamination } \\
\hline \multicolumn{7}{|l|}{ QA } \\
\hline DATA RELATIONSHIP & $* * * * * * * *$ & $* * * * * * * *$ & $* *+* * *+*$ & $m * * 0 * * * * *$ & 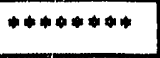 & $* 4+4 * *+*$ \\
\hline \multicolumn{7}{|l|}{ Generate } \\
\hline \multicolumn{7}{|l|}{ Store/Distribute } \\
\hline \multicolumn{7}{|l|}{ Use - Required } \\
\hline \multicolumn{7}{|l|}{ Use - Helpful } \\
\hline \multicolumn{7}{|l|}{ Statistical Anal. } \\
\hline \multicolumn{7}{|l|}{ Graphics/Map } \\
\hline \multicolumn{7}{|l|}{ Report } \\
\hline DATA SYSTEM & $* * * * * * * *$ & $m * * * * * * *$ & $* * * * * * * *$ & $* * * * * * * *$ & $* * * * * * *$ & $* * * * * * * *$ \\
\hline \multicolumn{7}{|l|}{ Hardware PC/MAC } \\
\hline \multicolumn{7}{|l|}{ Workstation/VAX } \\
\hline \multicolumn{7}{|l|}{ IBM mainframe } \\
\hline Accessibility & $* * * * * * * *$ & $* * * * * * * *$ & $4 * * * * * * *$ & $* * * * * * * *$ & $\omega+4+\omega * *$ & $* * *+* * * *$ \\
\hline \multicolumn{7}{|l|}{ Classified/sensitive } \\
\hline \multicolumn{7}{|l|}{ Paper } \\
\hline \multicolumn{7}{|l|}{ Stand-alone PC } \\
\hline \multicolumn{7}{|l|}{ Multi-user system } \\
\hline \multicolumn{7}{|l|}{ Network } \\
\hline \multicolumn{7}{|l|}{ Tape/disk } \\
\hline Software & $* *+4 * * * *$ & $* * * * * * * *$ & $* * * * * * * *$ & $* * * * * * * *$ & $* * * * * * * *$ & $* * * * * * * *$ \\
\hline \multicolumn{7}{|l|}{ Dbase } \\
\hline \multicolumn{7}{|l|}{ Excel } \\
\hline \multicolumn{7}{|l|}{ Lotus } \\
\hline \multicolumn{7}{|l|}{ Oracle } \\
\hline \multicolumn{7}{|l|}{ SAS } \\
\hline \multicolumn{7}{|l|}{ GIS } \\
\hline \multicolumn{7}{|l|}{ Graphics } \\
\hline Other & & & & & & \\
\hline
\end{tabular}

-See Attachment 1

'See Attachment 2 
Form 3. Evaluation of $\mathrm{CDB}$ and $\mathrm{CDB}$ GIS Functions

\begin{tabular}{|c|c|c|c|c|}
\hline FUNCTION ${ }^{2}$ & Essential & Important & Useful & Not needed \\
\hline \multicolumn{5}{|l|}{ Data merging } \\
\hline \multicolumn{5}{|l|}{ Data diversity } \\
\hline \multicolumn{5}{|l|}{ Data import/export } \\
\hline \multicolumn{5}{|l|}{ Data intensive graphics } \\
\hline \multicolumn{5}{|l|}{ Data retrieval language } \\
\hline \multicolumn{5}{|l|}{ Documented editing } \\
\hline \multicolumn{5}{|l|}{ User interface } \\
\hline \multicolumn{5}{|l|}{ QA, statistics, mathematics } \\
\hline \multicolumn{5}{|l|}{ Relate to CDB GIS } \\
\hline \multicolumn{5}{|l|}{ Remote access } \\
\hline \multicolumn{5}{|l|}{ Report generation } \\
\hline $\begin{array}{l}\text { GEOGRAPHIC } \\
\text { INFORMATION SYSTEM }\end{array}$ & $* * * * * * * * * *$ & $* * * * * * * * * *$ & $* * * * * * * * * *$ & $* * * * * * * * * *$ \\
\hline \multicolumn{5}{|l|}{ Access to central CDB data } \\
\hline \multicolumn{5}{|l|}{ Digital data editing } \\
\hline \multicolumn{5}{|l|}{ Digital data import/export } \\
\hline \multicolumn{5}{|l|}{ Graphics inclusion } \\
\hline \multicolumn{5}{|l|}{ Known coordinate processing } \\
\hline \multicolumn{5}{|c|}{ Logical and spatial data retrieval } \\
\hline \multicolumn{5}{|l|}{ Network and $3 D$ analyses } \\
\hline \multicolumn{5}{|l|}{ Polygon processing } \\
\hline \multicolumn{5}{|l|}{ "Real map" generation } \\
\hline \multicolumn{5}{|l|}{ remote access } \\
\hline \multicolumn{5}{|l|}{ Structured digital GIS data } \\
\hline User-friendly interface & & & & \\
\hline
\end{tabular}

${ }^{1}$ See Attachment 3

${ }^{2}$ See Attachment 4 


\section{ATTACHMENT' 1}

\section{Definitions of Environmental Data Categories on Form 2}

The environmental data have been categorized into major disciplinary groups for the purpose of indicating the diversity of environmental data within each data management program. The categories will also be used to indicate the disciplinary interactions required for analyses conducted by the users. The categories are purposefully general with broad definitions. Refinement of the exact types and distribution of environmental data will be determined after the preferred alternative for the system has been determined.

Air

- Meteorology (temperature, precipitation, cloudiness, wind speed and direction, and thermal profiles).

- Climate (average temperatures and precipitation), atmospheric chemistry (ion, gas, and suspended solid concentrations).

- Miscellaneous (visibility, air color, odor, etc.).

Surface Water

- Water chemistry.

- Physical (conductivity, turbidity, suspended solids, and temperature).

- Flow, volume.

\section{Groundwater}

- Parameters similar to surface water.

- Depth-to-water and other hydrology measurements.

- Well construction information.

\section{Soils/Geology}

- Soil chemistry.

- Soil texture and physics (permeability, air space, etc.).

- Soil profile.

- Sediment texture and chemistry.

- Geologic strata (depth, thickness, and rock type).

- Geologic characteristics (permeability, rock chemistry, etc.).

- Borehole data.

\section{Biology}

- Biotic samples (benthos, fish, vegetation, wildlife, populations, biomass, and bacteria).

- Chemical analyses of tissues.

\section{Map}

- Reference map data [data for geographic features that are not determined by the activities of the project (e.g. roads, buildings, streams, topography, etc.)].

- Project map data (geographic data that describe the location of project activities such as sample locations, test facility locations, contamination locations, etc.). 


\section{ATTACHMENT 2}

\section{Definitions of Data Management and Reporting Categories for Form 2}

The following sections describe the general categories of the rows in the survey table.

\section{Data Purpose}

The categories of data purpose are used to indicate the general intent of the data collection activities. Are the data collected for a background, compliance, or baseline type of routine measurement? Are the data collected in search of or in response to some specific contamination? Are QA data collected and processed?

\section{Data Activities}

The data activity categories are used to indicate the respondent's role in data management and reporting practices (i.e., what tasks do they perform on the data?).

Generate. Does this program dictate the initial collection and storage of the data?

Store/distribute. Does this program have the responsibility to be the "official repository and distributor" of the data?

Use-required. Is the use (access, analysis, and reporting) of these data required? Data may be required even though the data are not directly generated or stored by this program. This is an index of the required amount of "data sharing" in the current operation

Use-helpful. Is the use (access, analysis, reporting) of these data helpful in the interpretation of the project's data? Is access to these data types optional? This class of utilization identifies how "data sharing" could enhance the activities preformed by the users.

Statistical analysis. Does this program perform statistical analyses on the data (e.g., frequencies, means, standard deviations, t-test, ANOVA, regression, etc.)?

Would statistical analyses with this data category be helpful?

Report. Does this program have the responsibility to report the data? Does this program generate (summarize, tabulate, and format data) the report?

Graphics/Maps. Does this program use data to produce graphs or maps?

\section{Data System}

The items under Data System are used to indicate the general type of hardware and software used to manage the data. The type of accessibility of these systems is also useful for evaluating the feasibility of $\mathrm{CDB}$ alternatives. More than one system may be in use for a particular data category. Please check all systems that are used. 


\section{ATTACHMENT 3}

\section{Definitions of Value Categories for Form 3}

\section{Essential Functions}

Essential functions are those that are considered to be absolutely necessary for the $\mathrm{CDB}$ data base system. Without all of them, an alternative for the CDB will not acceptably meet the minimal objectives of the project.

\section{Important Functions}

Important functions are those that are not essential or necessary for the operation of the $\mathrm{CDB}$ but whose existence will significantly contribute to the success of the CDB. The absence of an important function will result in the $\mathrm{CDB}$ operating in a noticeably more indirect and error-prone manner.

\section{Useful Functions}

Useful functions are other data management functions that can be readily integrated into a data base system. Useful functions are advanced functions that will contribute to ancillary needs of the users. These functions are not essential to the CDB operation, but their existence will make a positive contribution. 


\section{ATTACHMENT 4}

\section{Definitions of Function Categories for Form 3}

\section{Data Base Functions}

\section{Data Base Merging and Relationship}

The CDB system will be composed of a wide diversity of data sets that must be joined (merged or related) on an "as needed" basis to formulate the requested data. Because requests will be a frequent and diverse activity, the facility to temporarily connect data sets should be fairly comprehensive. The data structure will be limited by this capability.

\section{Data Diversity}

The CDB system should be able to process and report all types of data (e.g., IDs, numeric, character, multiword strings, text blocks, time, date, etc.) All of these data should be equally addressable with full format and logical functions. Absence of this functionality could result in the handling and conversion of data in multiple systems.

\section{Data Import and Export}

The CDB is expected to receive data from several sources, and it should have a substantial capability to import varied data formats. The distribution of data to other systems and agencies also requires the ability to export data in numerous formats. The functionality of data import/export is defined to be the unattended and automatic conversion of data and its data definition (variable names, type, etc.) from one system to another.

\section{Data-Intensive Graphics}

Data-intensive graphics is a portion of the report generation and QA analysis methods. A graphics capability that can display data intensive information (detailed histograms, scatter plots, and 3D surfaces) that is internal to the CDB system would minimize data conversion and transfer for graphics generation.

\section{Data Retrieval Facility (language)}

A data retrieval facility (language and logic) that can handle routine and custom data requests should be a feature of the $\mathrm{CDB}$ system. A facility or language for data retrieval should be used so that requests can be performed at a "high level" with a minimal amount of error. Because not all of the requests can be "pre-programmed," this language feature is also helpful to meet the diversity of requests anticipated.

\section{Documented Transaction Processing (editing)}

The legal and regulatory nature of the $\mathrm{CDB}$ data results in several requirements for data documentation. Therefore, the $\mathrm{CDB}$ system should have an automated method of maintaining an "audit log" all of the additions and corrections to the CDB. This "audit log" should also be in some form of a data base so that computer-based retrieval and tabulation of the log can be performed. 


\section{User Interface}

The CDB user community will be diverse in its training, location, and needs. A user interface should be used to make the system accessible to many types of users. The CDB should have a readily developable user interface "tool kit" (e.g., macro language, menu language, etc.). Development without this "tool kit" would result in increased costs, time, and errors.

\section{QA, Statistics, and Mathematical Operations}

Statistical analyses for data QA and the user applications should be an integral part of the $\mathrm{CDB}$. Mathematical functions should also be useful for units conversion and tabulation of data within the CDB.

\section{Relate to CDB GIS}

A portion of the retrieval, subsetting, and analysis of the CDB should be implemented through the $\mathrm{CDB}$ GIS. The $\mathrm{CDB}$ data should be readily accessible to $\mathrm{CDB}$ GIS so that data conversion efforts and potential errors are minimized.

\section{Remote Access}

The user community of the CDB will not be restricted to Energy Systems staff. It will also include OR, TDHE, and EPA staff in a variety of locations. Therefore, the CDB system must be accessible by way of dial-up, system select, and ethernet (Internet) connections. Remote access also means that $\mathrm{CDB}$ users are not required to use specific CDB hardware (terminals, PCs, or workstations).

\section{Report Generation}

The CDB users will have a wide variety of report generation needs. The CDB system should have a report generation facility (a "tool kit" similar to the user interface) with a high-level language or template for format and tabulation specifications embedded in it.

\section{Geographic Information System Functions}

\section{Access to Central CDB Data}

The CDB GIS should have an expedient means of either accessing or incorporating data from the $\mathrm{CDB}$ to ensure that data from the $\mathrm{CDB}$ can be spatially retrieved as needed. Access to CDB data could be either by direct access or the translation of data between the CDB and its GIS.

\section{Digital Data Editing}

The CDB GIS should have its own procedures for editing and maintaining digital data. This editing should include functions that allow the graphic revision (pointing and relocating) of digital data. The GIS software should also have procedures to re-establish spatial relationships after the revisions. Spatial relationships include the identification and closure of polygons and the joining of line ends.

\section{Digital Data Import/Export}


The CDB GIS should have capabilities to import and export digital data. The CDB GIS will receive and distribute digital data from several sources within Energy Systems (e.g., Engineering, ERD, ESD, Compliance, Waste Management, and Planning), other federal and state agencies (e.g., USGS, EPA, and ATSDR), and subcontractors (e.g., Bechtel and SAIC). The CDB GIS should be able to process digital data in a variety of formats including ARC/INFO, DXF, DLG, IGES, and SIF.

\section{Graphics Inclusion}

The CDB GIS should be able to incorporate graphics from tabular CDB data in its display and maps. These graphics should include "data intensive" graphs such as scatter plots, bar charts, and line graphs. The inclusion of the graphics may be limited to one or two per map to present ancillary data. Complex pattern interpretation can also be enhanced when the 10 s and 100 s of small graphs (e.g., bar graphs) are spatially oriented on a map.

\section{Known Coordinate Processing}

The CDB GIS should have a documented process for transforming and projecting multiple coordinate systems. Because the GIS data for the $\mathrm{CDB}$ will include several facilities and multiple coordinate systems, known coordinate processing is necessary for the CDB GIS. The map data for the CDB should also have a describable history.

\section{Logical and Spatial Data Retrieval}

The CDB GIS should have the capability to retrieve subsets of objects [points (wells), lines (pipelines), or areas (contamination zones)] based on logical criteria (e.g., select all wells with depth greater than 50) and spatial selection (e.g., select all wells in a study area polygon) for GIS processing and map display. The logical subsetting should also allow for the specification of compound rules involving more than one parameter and/or range and spatial selection. The GIS should be able to display tabular data associated with the objects after subsetting.

\section{Network and 3D Analyses}

A GIS with network analysis can determine routing alternatives along linear pathways. Determination of slope, aspect, volume, contours, watersheds, and 3D perspectives can be performed with 3D analyses.

\section{Polygon Processing}

The CDB GIS should have the capability to determine in which polygon a point or line is contained. This capability also includes the overlaying of more than one layer of polygons that results in a set of composite polygons. The spatial selection of the data is limited without this function.

\section{"Real Map" Generation}

The CDB GIS should be able to generate a "real map" (i.e., one that is based on an identifiable coordinate system). "Real map" generation also implies that the GIS has the capability to generate medium- to high-quality plots to scale in useful sizes (page size for reports and large 3 by $5 \mathrm{ft}$ size for analyses). "Real mapping" should be used for the 
proper reporting of feature locations. It also should be used for interrelating digital data from more than one map data set.

\section{Remote Access}

The CDB is a multisite project, and the users of the GIS are not going to be centrally located. Therefore, the CDB GIS should be able to generate graphic displays on remote systems (terminals, PCs, or workstations). The communications protocols for this remote access should be minimal to allow the maximum options for access (e.g., the CDB GIS should be accessible from System Select or MMES ethernet to allow widely distributed and dial-up access). High-speed access with Energy Systems network should also be an option so that remote access of the CDB GIS is not always limited to very low communication rates.

\section{Structured Digital GIS Data}

The CDB GIS should have structured digital data. This means that the GIS objects (points, lines, and polygons) can be stored and manipulated as identifiable graphic (and geographic) entities. The structure should also allow for data to be thematically identifiable (e.g. roads, streams, and buildings) for processing and display as needed. A second level of structure useful for GIS data is that it has objects that have a one-to-one correspondence to the geographic features. This means that each point (e.g., well) is represented by one XY, and each line is a chain of XYs. The digital data for each object should be accessible for independent processing (e.g., editing and display).

The objects (points, lines, and polygons) in the digital GIS data should also have a defined (one-to-one) relationship with tabular data records that are associated with the objects. The tabular data should include the capacity for several values of all data types (floating point numeric, integer numeric, character, etc.) The relationship between tabular data and geographic objects enables the spatial selection and logical subsetting previously described.

\section{User-friendly Interface (User Menu)}

A user menu interface for the CDB GIS would enable access by intermittent users of the CDB GIS. An initial form of the menu should come with the GIS software. It should also have facilities for menu customization so that it can be reorganized for optimal CDB usage. 


\section{DISTRIBUTION}

1. L. J. Allison

2. L. D. Bates

3. J. B. Bradshaw

4. E. A. Bright

5. J. B. Cannon

6. P. R. Colernan

7. K. W. Cook

8. T. K. Cothron

9. J. H. Cushman

10. G. D. Dalton

11. M. F. P. Delozier

12. R. C. Durfee

13. J. J. Edwards

14. D. E. Fowler

15. S. B. Garland

16. C. W. Gehrs

17. M. J. Gentry

18. P. L. Goddard

19. C. D. Goins

20. P. J. Halsey

21. B. K. Harrington

22. S. G. Hildebrand

23. L. A. Hook

24. P. Kanciruk

25. B. L. Kimmel

26. E. A Krispin

27. A. J. Kuhaida

28. M. L. Land

29. F. E. Latham

30. V. Legg
31-33. D. M. Matteo

34. R. A. McCord

35. R. W. McNeil

36. B. E. Meadows

37. R. W. Meehan

38. R. J. Olson

39-40. P. T. Owen

41. D. E. Reichle

42. G. E. Rymer

43. P. A. Schrandt

44. F. E. Sharples

45. D. S. Shriner

46. J. L. Smyre

47. S. H. Stow

48. D. W. Swindle

49. J. K. Thomas

50. E . P. Tinnel

51. G. L. Underberg

52. R. I. Van Hook

53. R. J. Verastegui

54. D. R. Watkins

55. R. A. Whitaker

56. R. K. White

57. L. D. Voorhees

58. B. C. Zygmunt

59. Central Research Library

60 64. ESD Library

65-69. ER Document Management Center

70-71. Laboratory Records Dept.

72. ORNL Patent Section

73. Office of Assistant Manager for Energy Research and Development, DOE Oak Ridge Field Office, P.O. Box 2001, Oak Ridge, TN 37831-8600

74. G. W. Bodenstein, MS-EW91, DOE Oak Ridge Field Office, P.O. Box 2001, Oak Ridge, TN 37831

75. S. G. Dyer, MS-SE31, DOE Oak Ridge Field Office, P.O. Box 2001, Oak Ridge, TN 37831

76. P. H. Edmonds, Radian Corporation, 120 South Jefferson Circle, Oak Ridge, TN 37830

77. J. F. Franklin, Bloedel Professor of Ecosystem Analysis, College of Forest Resources, University of Washington, Anderson Hall AR-10, Seattle, WA 98195 
78. R. C. Harriss, Institute for the Study of Earth, Oceans, and Space, Science and Engineering Research Building, University of New Hampshire, Durham, NH 03824

79. G. M. Hornberger, Professor, Department of Environmental Sciences, University of Virginia, Charlottesville, VA 22903

80. G. Y. Jordy, Director, Office of Program Analysis, Office of Energy Research, ER-30, G-226, U.S. Department of Energy, Washington, DC 20545

81-84. W. E. Murphie, Department of Energy, Office of Environmental Restoration, Eastern Area D\&D Branch, EM-423 (GTN), Washington, DC 20545

85. R. H. Olsen, Professor, Microbiology and Immunology Department, University of Michigan, Medical Sciences II, \#5605, 1301 East Catherine Street, Ann Arbor, MI 48109-(0620

86. A. Patrinos, Acting Director, Environmental Sciences Division, Office of Health and Environmental Research, ER-74, U.S. Department of Energy, Washington, DC 20585

87-88. R. C. Sleeman, DOE Oak Ridge Field Office, P.O. Box 2001, Oak Ridge, TN $37831-8540$

89-90. J. T. Sweeney, DOE Oak Ridge Field Office, P.O. Box 2001, Oak Ridge, TN $37831-8540$

91. F. J. Wobber, Environmental Sciences Division, Office of Health and Environmental Research, ER-74, U.S Department of Energy, Washington, DC 20585

92-93. Office of Scientific and Technical Information, P.O. Box 62, Oak Ridge, TN 37831 

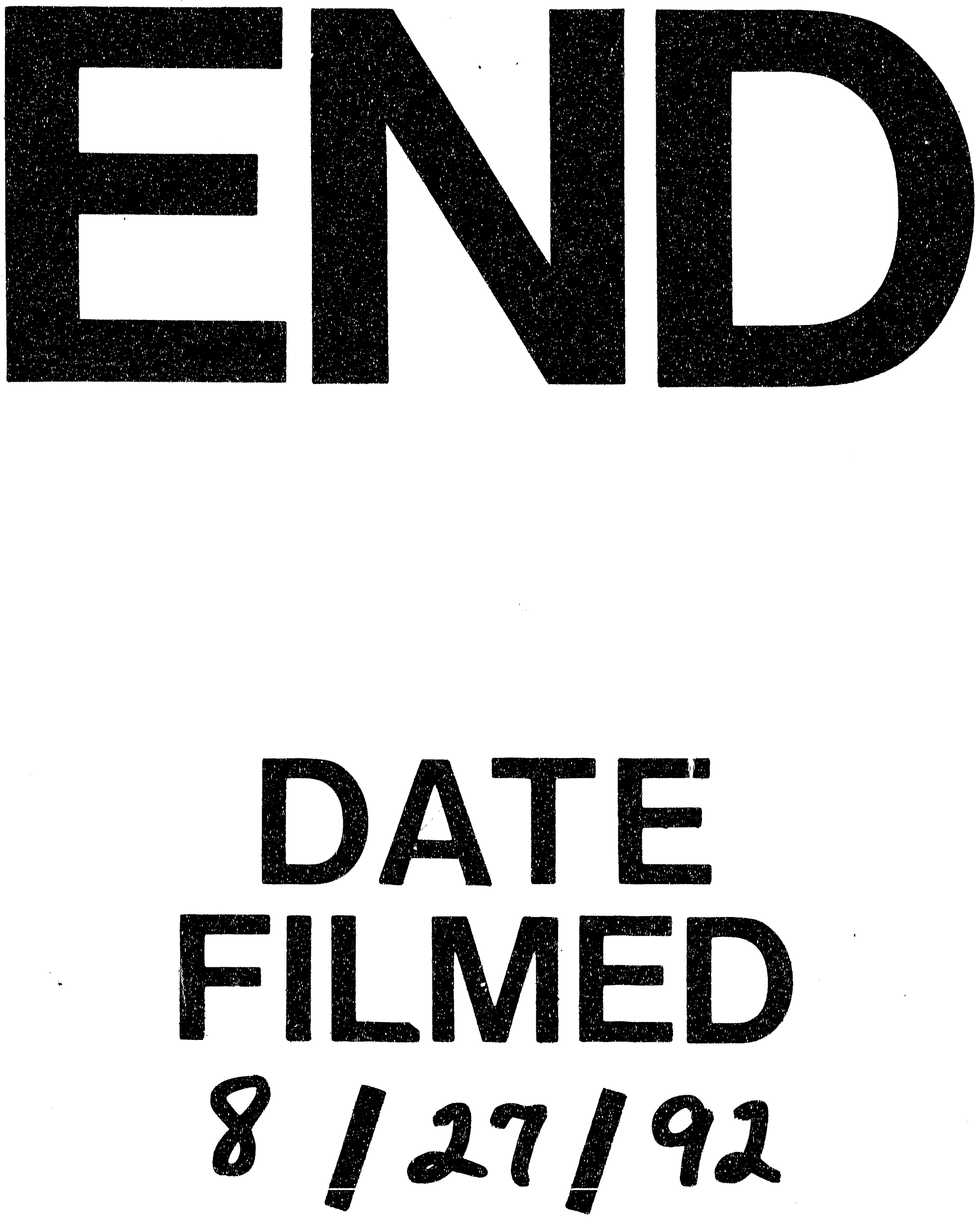

竫 
